\title{
Interdecadal seesaw of precipitation variability between North China and the Southwest US
}

Article

Accepted Version

Yang, Q., Ma, Z., Wu, P., Klingaman, N. P. and Zhang, L. (2019) Interdecadal seesaw of precipitation variability between North China and the Southwest US. Journal of Climate, 32. pp. 2951-2968. ISSN 1520-0442 doi: https://doi.org/10.1175/JCLID-18-0082.1 Available at https://centaur.reading.ac.uk/82526/

It is advisable to refer to the publisher's version if you intend to cite from the work. See Guidance on citing.

To link to this article DOI: http://dx.doi.org/10.1175/JCLI-D-18-0082.1

Publisher: American Meteorological Society

All outputs in CentAUR are protected by Intellectual Property Rights law, including copyright law. Copyright and IPR is retained by the creators or other copyright holders. Terms and conditions for use of this material are defined in the End User Agreement.

www.reading.ac.uk/centaur 
Central Archive at the University of Reading

Reading's research outputs online 


\section{Interdecadal seesaw of precipitation variability between North China and the}

2

17 Corresponding author: Dr. Zhuguo Ma Beijing, China

\section{Southwest US}

Qing Yang ${ }^{1}$, Zhuguo $\mathrm{Ma}^{1,2}$, Peili $\mathrm{Wu}^{3}$, Nicholas P. Klingaman ${ }^{4}$, Lixia Zhang ${ }^{5}$

1. Key Laboratory of Regional Climate-Environment Research for Temperate East Asia, Institute of Atmospheric Physics, Chinese Academy of Sciences, Beijing, China

2. University of Chinese Academy of Sciences, Beijing, China

3. Met Office Hadley Centre, Exeter EX1 3PB, UK

4. National Centre for Atmospheric Science, Department of Meteorology, University of Reading, Reading, UK

5. The State Key Laboratory of Numerical Modeling for Atmospheric Sciences and Geophysical Fluid Dynamics (LASG), Institute of Atmospheric Physics, Chinese Academy of Sciences, Beijing, China

Submitted to Journal of Climate

Revised February 2019

Key Laboratory of Regional Climate-Environment Research for Temperate East Asia,

Institute of Atmospheric Physics, Chinese Academy of Sciences, Chao Yang District,

E-mail: mazg@tea.ac.cn. Tel: +86-10-82995047 
This paper reports a consistent seesaw relationship between interdecadal

24 precipitation variability over North China and the Southwest United States (US), which

25 can be found in observations and simulations with several models. Idealized model

26 simulations suggest the seesaw could be mainly driven by the Interdecadal Pacific

27 Oscillation (IPO), through a large-scale circulation anomaly occupying the entire

28 northern North Pacific, while the Atlantic Multidecadal Oscillation (AMO) contributes

29 oppositely and less. Modulation of precipitation by the IPO tends to be intensified when

30 the AMO is in the opposite phase, but weakened when the AMO is in the same phase.

31 The warm IPO phase is associated with an anomalous cyclone over the northern North

32 Pacific and consequently, anomalous southwesterly winds bring more moisture and

33 rainfall to the Southwest US, while northwesterly wind anomalies prevail over North

34 China with negative rainfall anomalies. The east-west seesaw of rainfall anomalies

35 reverses sign when the circulation anomaly becomes anticyclonic during the cold IPO

36 phase. The IPO-related tropical SST anomalies affect the meridional temperature

37 gradient over the North Pacific and adjacent regions and the mean meridional

38 circulation. In the northern North Pacific, the atmospheric response to IPO forcing

39 imposes an equivalent barotropic structure throughout the troposphere. An important

40 implication from this study is the potential predictability of drought-related water

41 stresses over these arid and semiarid regions, with the progress of our understanding

42 and prediction of the IPO and AMO. 
Key words: precipitation variability, interdecadal seesaw, Interdecadal Pacific Oscillation, drought, water resources

\section{Introduction}

Precipitation variability has profound impacts on society and ecosystems because it is closely related to drought, floods and water resources. Any useful prediction skills on precipitation will be greatly beneficial and normally associated with certain climate modes within the coupled climate system, such as the Interdecadal Pacific Oscillation (IPO; Zhang et al. 1997; Power et al. 1999) and the Atlantic Multidecadal Oscillation (AMO; Kerr 2000). The AMO, for example, is found to be strongly coupled with the global water cycle (Vellinga and Wu, 2004). Anthropogenic climate change is also affecting the global water cycle with regional impacts (Wu et al. 2013; 2015; Zhang et al. 2017; Kang and Eltahir, 2018). There are certain regions over the world, which are particularly sensitive to episodes of climate related precipitation variability on decadal or multidecadal timescales, such as North China and the Southwest United States (US). Both North China and the Southwest US are typical arid and semi-arid regions, often hard hit by serious droughts. Many studies have attributed their interdecadal precipitation variability to the IPO, although the underlying mechanism of which is still under intensive debate (Farneti et al. 2014; Di Lorenzo et al. 2015; Newman et al. 2016; Si and Hu 2017; Henley 2017; Henley et al. 2017). The warm IPO phase corresponds to below-normal precipitation over North China (Ma and Shao 2006; Ma 2007; Zhou et al. 2013; Qian and Zhou 2014; Huang et al. 2017), but above-normal precipitation over the 
Southwest US (Meehl and Hu 2006; Dai 2013), implying an obvious out-of-phase relationship for precipitation regime shift. Following the IPO cold-to-warm phase shift around 1977, there is an evident drying trend over North China, whereas a significant wetting trend is shown in the Southwest US since the 1950s; increased precipitation in the Huang-Huai River region (southern North China) after 2000, and a robust drying trend over the Southwest US since the 1980s are thought to be largely caused by the IPO warm-to-cold phase transition around 1999 (Ma 2007; Zhu et al. 2011; 2015; Dai 2013; Chylek et al. 2014; Qian and Zhou 2014). Additionally, the AMO contributes to the out-of-phase decadal precipitation pattern (Li and Bates 2007; Mo et al. 2009; Schubert et al. 2009; Feng et al. 2011; Zhu et al. 2016; Si and Ding 2016). The warm AMO phase tends to induce a stronger East Asia Summer Monsoon (EASM), leading to more northward transport of moisture and enhanced rainfall over North China, but dry conditions in the Southwest US (Lu et al. 2006; Sutton and Hodson 2005; 2007; Hu et al. 2011; Feng et al. 2011). The combined effects of the IPO and AMO are complicated and important (Schubert et al. 2009; Zhu et al. 2016; Si and Hu 2017; Yang et al. 2017). For instance, more than half (52\%) of the spatial and temporal variance in multidecadal drought frequency over the US is attributable to the AMO and the Pacific Decadal Oscillation (PDO, Mantua et al. 1997; Mantua and Hare 2002), which is the North Pacific component of the IPO (McCabe et al. 2004).

The purposes of this study are to identify the interdecadal seesaw of precipitation variability between North China and the Southwest US, to further understand the associated formation mechanism related to the IPO and AMO, and to answer why there 
is an out-of-phase decadal precipitation pattern between North China and the Southwest US through analysis of decadal ocean forcings.

Although many studies have investigated the contrasting relationship of precipitation variability between Asia and North America (e.g., Lau and Weng 2002; Lau et al. 2004; Li et al. 2005; Ma and Fu 2007; Hua et al. 2011; Zhao et al. 2011; 2016; Wang et al. 2014; Fang et al. 2014; 2015; Yang and Fu 2016; Zhu and Li 2016), the circulation mechanism for the seesaw relationship remains unclear. This is because that previous researches have focused on inconsistent study areas (Zhao et al. 2011; 2016; Fang et al. 2015), time scales (Lau and Weng 2002; Lau et al. 2004; Fang et al. 2014; Wang et al. 2014), and precipitation-related variables (Li et al. 2005; Yang and Fu 2016). Additionally, for attribution of precipitation variability, more attentions have been paid to the Asian-Pacific Oscillation (Zhao et al. 2011; Fang et al. 2015), East Asian subtropical monsoon heating (Zhu and Li 2016), Eurasian non-monsoon land heating (Zhao et al. 2016), and North Pacific sea surface temperature (SST) anomaly (Lau and Weng 2002; Lau et al. 2004), rather than the IPO and AMO. We aim to address these shortcomings in this study.

The observed precipitation records are shorter than 150 years over the US and the quality of the records decline significantly backward in time. In China, most of meteorological stations were established after 1960s and only few stations were available before 1960s, resulting in only about 60 stations with approximately 100 years of precipitation observations. These datasets are just enough to cover one (or two) full cycles of the AMO and the IPO, which limits their utility for diagnosing robust 
110 (2016) indicated that climate impacts correlated with the PDO are different from

111 climate impacts that are predicted by the PDO, because that climate impacts and the

112 PDO may be both driven by a common forcing function. It is difficult to distinguish

113 these two relationships in observation. Atmospheric general circulation models

114 (AGCMs) with prescribed observed or idealized SST patterns (e.g., Li et al. 2010; Hu et

115 al. 2011; Dai 2013; Schubert et al. 2009) are effective tools to confirm or reject

116 conclusions reached from observational analysis. Thus, in addition to observational and

117 reanalysis data, a series of AGCM experiments designed by the US Climate Variability

118 and Predictability (CLIVAR) Drought Working Group (Schubert et al. 2009) are also

119 employed in this study. As they are not fully coupled, there experiments are not suitable

120 to disentangle air-sea interaction. Detailed physical mechanisms of the interdecadal

121 oceanic modes and their potential influence to the seesaw relationship have not been

122 addressed in this study, and further follow-up work is needed.

123 The rest of the paper is organized as follows. In section 2, we describe the data,

124 AGCM experiments and methods used in this study. The observed seesaw pattern and

125 associated circulation are presented in section 3 . The possible mechanisms are provided

126 in section 4. A summary and discussion are given in section 5.

\section{2. Data and methods}

\section{a. Data}

130 The following datasets are used in this study. 
131 1) Global merged monthly precipitation (based on gauge records) for 1850-2014 on a

$1322.5^{\circ}$ latitude $\times 2.5^{\circ}$ longitude grid obtained from Dai $(2011 ; 2013)$. We focused on the

133 period 1900-2014 because precipitation observations are sparse over China before

134 around 1900.

135 2) Global land monthly precipitation for $1901-2015$, with a high resolution of $0.5^{\circ}$

136 latitude $\times 0.5^{\circ}$ longitude, obtained from CRU TS4.0 (University of East Anglia

137 Climatic Research Unit, 2017).

138 3) Chinese long-term gridded precipitation data for 1900-2009 obtained from the China 139 Meteorological Administration.

140 4) Global atmospheric reanalysis monthly data for circulation for $1948-2016$ on a $2.5^{\circ}$

141 latitude $\times 2.5^{\circ}$ longitude grid, from the U.S. National Centers for Environmental

142 Prediction/National Center for Atmospheric Research (NCEP-NCAR; Kalnay et al. 143 1996).

144 5) Global gridded monthly SST for 1901-2016 on a $2^{\circ}$ latitude $\times 2^{\circ}$ longitude grid, from 145 the National Oceanic and Atmospheric Administration Extended Reconstructed SST 146 version 4 (ERSST v4; Huang et al. 2015).

147 6) The annual IPO index for 1920-2015, from Dai (2013), who defined the smoothed

148 (by applying a 9-year moving average twice) associated principle component of the 149 second leading empirical orthogonal function (EOF) of the 3-year moving averaged 150 SST from the Hadley Centre Sea Ice and Sea Surface Temperature dataset (HadISST;

151 Rayner et al. 2003), using data for $1920-2011$ and $60^{\circ} \mathrm{S}-60^{\circ} \mathrm{N}$.

152 7) The monthly AMO index for 1856-2016 (Enfield et al. 2001) downloaded from 


\section{b. AGCM experiments} experiments were prescribed as follows.

1) The Rotated Empirical Orthogonal Function (REOF) method was applied to global annual-mean SST anomalies (Rayner et al. 2003) from 1901 to 2004 to obtain the leading patterns of SST anomalies.

2) The REOF2 (Fig. 1a) was scaled by $\pm 2 \sigma$ ( $\sigma$ is the standard deviation of the associated Rotated Principal Component (RPC2, Fig. 1b)) and then superimposed onto the 1901-2004 monthly climatology, forming a forcing SST anomaly called the Pacific pattern.

3) Applying the method in (2) to the REOF3 (Fig. 1c) yields the Atlantic pattern. anomaly, and RPC2 is significantly correlated with the IPO index; thus, the Pacific pattern is deemed the IPO in this study. Likewise, the Atlantic pattern is deemed the

171 AMO. Note that the prescribed SST fields vary monthly with the climatological

172 (1901-2004) seasonal cycle, but have no inter-annual or longer-term variability.

173 We focused on nine baseline experiments, which are combinations of the Pacific

174 (P) and Atlantic (A) patterns of cold (denoted by $c$; scaled by $-2 \sigma)$, neutral ( $n$; zero 
175 anomaly), and warm ( $w$; scaled by $+2 \sigma$ ) anomalies (denoted by PxAy shown in Table 1,

176 here $\mathrm{x}, \mathrm{y}=c, n, w)$. These baseline experiments were performed by five AGCMs: the

177 NASA Seasonal-to-Interannual Prediction Project AGCM (NSIPP1, Bacmeister et al.

178 2000), the Global Forecast System AGCM (GFS, Campana and Caplan 2005), the

179 Geophysical Fluid Dynamics Laboratory AGCM (GFDL, Delworth et al. 2006), the

180 Community Atmospheric Model (CAM3.5, Chen et al. 2010), and the Community

181 Climate Model (CCM3, Kiehl et al. 1998). All simulations ran for 50 years, except the

182 GFS (35 years). Additional experiments (performed by only GFDL and NSIPP1)

183 forced by the tropical SST component of the Pacific pattern (Fig. 1a, blue box) were

184 also analyzed. For more information and an overview of the US CLIVAR Drought

185 Working Group, please see Schubert et al. (2009).

186

c. Methods

We focused on interdecadal precipitation variations and used a 9-year moving average twice, which is equivalent to a 17-year low-pass filter with unequal weights, to remove short-term variations. Regression analysis and epoch composites were

191 employed to depict the spatial patterns of anomalous SST and atmospheric circulation

192 associated with the precipitation and the IPO. The threshold of $\pm 0.5 \sigma$ of the IPO index

193 was used to define the IPO cold and warm phases. The long-term trend in global SST

194 was removed by regressing the SST with the time series of global annual mean SST,

195 while the long-term trend in other variables was removed using a linear least square

196 fit. The Student's $t$-test (Wilks 2005) was used to test the difference of mean during 
197

198

199

different composite periods, and detect the statistical significance of linear regression coefficients and Pearson correlation coefficients, after adjusting the degrees of freedom (in supplement). In addition, simulations from all five AGCMs were averaged to obtain an ensemble mean, which often reduces model uncertainties introduced by sub-grid scale parameterizations and produces signals closer to observations (Rowell 1998;

Wang et al. 2005; Mo et al. 2009).

\section{Interdecadal seesaw and associated circulations}

Figure 2a shows detrended and smoothed regional average precipitation anomalies over North China and the Southwest US, as well as the IPO and AMO indices. Precipitation variations over North China are significantly negatively correlated with those over the Southwest US, with wet (dry) over North China aligning with dry (wet) over the Southwest US, implying an apparent interdecadal seesaw pattern.

Note that a significant positive correlation is found between Southwest US precipitation and the IPO index, with the maximum correlation $(r=0.90)$ at zero lag, implying they vary in phase. North China precipitation is significantly anti-correlated with the IPO index at zero lag, suggesting they vary out of phase. This means that the IPO may be associated with the interdecadal seesaw pattern, with the warm IPO phase aligned with below-normal precipitation over North China but above-normal precipitation over the Southwest US and the cold IPO phase aligned with wet over

North China but dry over the Southwest US (Fig. 2b). It is also noted that the maximum 
negative correlation $(r=-0.62)$ occurs when the IPO leads North China precipitation by about 8 years (Fig. S2 in supplement). The 8 -year lagged anti-correlation could be 221 one reason why the PDO trend during 1971-2012 is nearly zero, however, there is a 222 significant decline in North China precipitation mentioned by Zhou et al. (2013). Unlike the IPO, the AMO has an insignificant positive correlation with North

224 China precipitation at zero lag, implying the AMO's contemporaneous influence on 225 precipitation is smaller than the IPO's. The maximum positive correlation $(r=0.85)$ is 226 found when the AMO leads precipitation by about 15 years, or approximately 227 one-quarter of an AMO cycle. The AMO has a significant anti-correlation with 228 precipitation over the Southwest US, with maximum negative correlation $(r=-0.81)$ 229 when the AMO leads precipitation by about 11 years. This implies that the AMO has 230 opposite effect on the interdecadal seesaw with respect to the IPO. Additionally, the 231 AMO can only strengthen (weaken) the magnitude of the IPO-induced precipitation anomaly, when the AMO is out of phase (in phase) with the IPO (Fig. 2b), respectively. We also performed the same analysis using the CRU TS4.0 precipitation data. The 234 results (Fig. S1 in supplement) are analogous to those shown in Fig. 2a using the Dai 235 precipitation data, indicating that the relationships are robust and not sensitive to the 236 choice of data.

237 Given that the IPO may play a dominant role in the interdecadal seesaw pattern, 238 the IPO phase composite anomalies of SST and precipitation over North China and the 239 Southwest US are shown in Fig. 3. During the first cold IPO phase (1947-1972), 240 precipitation shows a north-south dipole, with above-normal precipitation over North 
241 China but below-normal precipitation over South China (Fig. 3a). Meanwhile, most of

242 the contiguous US receives below-normal precipitation except parts of the northwest

243 and southeast, where precipitation increases (Fig. 3b). During the warm IPO phase

244 (1977-1998), the spatial pattern of precipitation anomalies resembles that associated

245 with the first cold IPO phase, but with opposite sign. However, note that the two cold

246 IPO phases have distinct precipitation anomalies. For the recent cold phase

247 (2003-2014), above- and below-normal precipitation is expected over North China and

248 the Southwest US, respectively. However, precipitation decreases in both regions. A

249 comparison of the SST anomalies associated with the two cold IPO phases (Fig. 3c and

250 3i), shows opposite-signed SST anomalies, except in the North Pacific. This implies

251 that other interdecadal SST modes, e.g., AMO, may influence regional precipitation

252 anomalies; over North China, their influences tend to be comparable to that of the IPO,

253 but over the Southwest US they are relatively smaller. In addition, the 8-year lag

254 anti-correlation between precipitation over North China and the IPO for 1920-2014 is

255 similar to that for 1920-2000 (Fig. S3 in supplement), suggesting that the lag

256 anti-correlation is robust. Therefore, the 8 years' lag could be another reason for the

257 negative precipitation anomaly in North China during the recent IPO cold phase, which

258 has thus far existed for only approximately a quarter of a traditional IPO cycle.

259 To explore global large-scale atmospheric circulation anomalies associated with

260 increased precipitation over North China and the Southwest US, some key circulation

261 variables as well as SST were separately regressed onto the smoothed regional mean

262 precipitation anomalies over the two regions (Fig. 4). 
264 feature is a basin-wide warming in the northern North Pacific and cooling in the

265 tropical eastern Pacific (Fig. 4a), which resembles the IPO cold phase (Fig. 3c). There

266 is an anomalously low sea-level pressure (SLP) over China and Mongolia, while an

267 anomalously high SLP occupies the entire northern North Pacific. A positive height

268 anomaly in the upper troposphere is also found over the northern North Pacific,

269 suggesting the anomalous high pressure has an equivalent barotropic structure (Fig. 4c).

270 It is associated with an anomalous anticyclone extending from west coast of North

271 America to east coast of Asia. The lower-tropospheric circulation over East China

272 features anomalous southwesterlies, indicating an enhanced EASM circulation. These

273 circulation anomalies favor water vapor transport from the tropics and convergence

274 into North China, associated with increased precipitation over North China but reduced

275 precipitation over South China.

276 Compared with North China, increased precipitation over the Southwest US is

277 associated with opposite-signed anomalies in SST and circulation. The spatial pattern

278 of SST anomalies is analogous to the warm IPO phase (Fig. 3f). The northern North

279 Pacific is also dominated by an equivalent barotropic structure, but it is an anomalous

280 low. The associated anomalous cyclone induces anomalous southwesterlies and

281 increased precipitation over the Southwest US (Fig. 4d). Meanwhile, anomalous

282 northerlies are found over East China, implying a weakened EASM and reduced

283 precipitation over North China. 


\section{Possible formation mechanism of the interdecadal seesaw}

\section{a. Impact of the IPO}

Illustrated in Fig. 5 are multi-model ensemble mean anomalies of regional mean annual and seasonal precipitation responses in the eight AGCM experiments over North China and the Southwest US. In PwAn (the Pacific warm SST anomaly and Atlantic SST in neutral condition), below-normal precipitation occurs over North China, whereas the Southwest US receives above-normal precipitation, implying a seesaw pattern. The seesaw pattern reverses sign in PcAn. The AMO also contributes to the seesaw pattern, but has the opposite influence, with wet (dry) anomalies over North China and dry (wet) anomalies over the Southwest US associated with PnAw (PnAc).

With respect to the annual-mean precipitation in PnAn, the IPO causes precipitation variations of approximately $6.4 \%$ and $39.8 \%$ of the mean over North China and the Southwest US, respectively, while the AMO only induces variations of approximately $4.1 \%$ and $13.5 \%$ of the mean. These results suggest that the IPO is the primary influence on the seesaw pattern; its modulation tends to be intensified when the AMO is in the opposite phase, but weakened when the AMO is in the same phase. Besides, note that the intermodel consensus is much stronger for the precipitation responses over the Southwest US than that over North China, implying that the linkage between the IPO (AMO) and precipitation variations is stronger over the Southwest US, whereas there are some uncertainties over North China.

Generally, the AGCMs in this study simulate well the observed contrasting precipitation variability between North China and the Southwest US, as well as the 
307 dominant role of the IPO in driving this contrast. The precipitation response over the

308 Southwest US to the IPO is much larger than that over North China. This is consistent

309 with Dong and Dai (2015), which found a robust precipitation response over the

310 Southwest US for two cold IPO phases in a CanAM4 simulation forced by observed

311 SSTs from 1950 to 2009, whereas the precipitation response was inconsistent over

312 North China. Additionally, the similarity between the precipitation responses in the

313 annual and seasonal averages, especially over the Southwest US, may be related to

314 imposing the annual-mean IPO or AMO SST anomaly onto the monthly climatology

315 (Schubert et al. 2009).

316 To clarify the impact of the IPO on the seesaw, Fig. 6 shows the annual-mean

317 atmospheric circulation response to PwAn and PcAn. In PwAn, the predominant

318 feature of the SLP (Fig. 6a) and height responses at $500 \mathrm{hPa}$ (Fig. 6c) is a negative

319 anomaly occupying the entire northern North Pacific, implying a deepened Aleutian

320 low. This is accompanied by a large-scale cyclonic anomaly extending from the west

321 coast of North America to northern China. Meanwhile, there is an anticyclonic anomaly

322 centered over the northwest Pacific. Combined, these circulations induce anomalous

323 northwesterlies over North China and southwesterlies over both the Southwest US and

324 South China, and a belt of anomalous moisture transport from the Bay of Bengal, South

325 China Sea and the subtropical Pacific to the west coast of North America (Fig. 6e). This

326 increased moisture transport is associated with a belt of increased precipitation,

327 including the Southwest US and South China (Fig. 6g). Less precipitation falls over

328 North China, related to the increase in moisture convergence over South China 
associated with the weakened EASM (Yang et al. 2017). The simulated circulation

330 patterns resemble those related to increased precipitation over the Southwest US in

331 observations (Fig. 4b and 4d). In PcAn (right column in Fig. 6), the spatial patterns of

332 the circulation responses are analogous to those in PwAn but with opposite signs, as

333 well as those related to increased precipitation over North China in observations (Fig.

$3344 \mathrm{a}$ and $4 \mathrm{c})$.

335 Both observations and simulations suggest the IPO-induced height anomaly over

336 the northern North Pacific is critical in driving the seesaw pattern, via opposing wind

337 and moisture anomalies on its eastern and western sides. Next, we consider the possible

338 mechanisms for this height anomaly.

339 In PwAn, warm SST anomalies over the equatorial central-eastern Pacific warm

340 the tropical troposphere through enhanced surface heat fluxes from the ocean to the

341 atmosphere (Fig. 7a). Meanwhile, a zonal belt of extensive cooling exists over

342 approximately $30^{\circ} \mathrm{N}-60^{\circ} \mathrm{N}$, which may be associated with changes in the eddy-driven

343 mean meridional circulation (Seager et al. 2003). Then, the meridional temperature

344 gradient (MTG), computed as the temperature difference from south to north,

345 strengthens over the region $15^{\circ} \mathrm{N}-45^{\circ} \mathrm{N}$, collocated with enhanced westerlies in the

346 upper troposphere via thermal wind balance. In the tropics and high latitudes, the

347 weakened MTG is associated with anomalous easterlies. Associated with these wind

348 anomalies is a dipole pattern of relative vorticity changes at $200 \mathrm{hPa}$ over the North

349 Pacific, with a cyclone over the northern North Pacific and an anticyclone over the

350 southern North Pacific, with a dividing line at approximately $40^{\circ} \mathrm{N}$ (Fig. $7 \mathrm{c}$ ). 
351 Consequently, an anomalous upper-troposphere low-pressure center forms over the 352 northern North Pacific.

353 On the other hand, the mean meridional circulation over the North Pacific changes 354 in response to the increased atmospheric heating over the tropical ocean. The thermally 355 direct Hadley cell is strengthened by enhanced tropical convection (Fig. 7g), itself due 356 to enhanced surface evaporation and low-level moisture convergence. The

357 strengthened descending motion in the subsiding branch of the Hadley cell, centered at 358 approximately $20^{\circ} \mathrm{N}$, aligns with an anomalous anticyclone at $850 \mathrm{hPa}$ (Fig. 7e). In the 359 lower troposphere, the northward flow from the subtropical anomalous anticyclone 360 converges in the mid-latitudes and enhances the ascending branch of the Ferrel cell,

361 forming an anomalous cyclone over the northern North Pacific. Therefore, in PwAn, a 362 barotropic low-pressure anomaly extends across the northern North Pacific, which is 363 clearly related to the planetary-scale response of the atmosphere to the tropical warm 364 SST anomalies.

365 Collocated with vertical velocity anomalies (upward-downward-upward from 366 south to north, Fig. $7 \mathrm{~g}$ ) over the North Pacific, there is above-normal precipitation in 367 the tropics $\left(10^{\circ} \mathrm{S}-10^{\circ} \mathrm{N}\right)$, below-normal precipitation in the subtropics $\left(10^{\circ} \mathrm{N}-30^{\circ} \mathrm{N}\right)$, and 368 above-normal precipitation in the mid-latitudes $\left(30^{\circ} \mathrm{N}-50^{\circ} \mathrm{N}\right.$, Fig. $\left.7 \mathrm{i}\right)$. Note that the 369 above-normal precipitation overlies cold SST anomalies across the northern North 370 Pacific. The opposing signs of the precipitation and SST anomalies suggests that the 371 increased precipitation is forced remotely, not by local SST anomalies (Wu and 372 Kirtman 2007), strengthening the conclusion that the negative height anomaly over the 
northern North Pacific is a response to the IPO-associated tropical warm SST anomalies via the atmospheric bridge.

Then, a question naturally arises: Do the tropical SST component of the IPO induce the height anomaly over the northern North Pacific? To answer the question, additional experiments (performed by only GFDL and NSIPP1) forced by the tropical SST component of the Pacific pattern were also analyzed and compared with the baseline experiments.

Overall, circulation responses in AGCMs forced by the tropical SST anomaly only (TP) support the above finding (Fig. 8). Like PwAn, TPwAn also induces a tripole pattern of temperature anomalies over the North Pacific (warm-cold-warm from south to north), which is associated with a tripole structure of zonal wind anomalies (easterlies-westerlies-easterlies), due to the MTG changes. These favor a dipole pattern of relative vorticity shear in the upper troposphere, with positive vorticity over the northern North Pacific and negative vorticity over south of it. The former is associated with a barotropic low-pressure anomaly, accompanied by a large-scale cyclonic flow over the northern North Pacific and adjacent regions in the lower troposphere.

Consequently, the seesaw pattern forms (Fig. 9 and Fig. S5 in supplement), characterized by dry over North China and wet over the Southwest US. The atmospheric processes associated with PcAn (right column in Fig. 7) and TPcAn (Fig. S4 in supplement) resemble those associated with PwAn and TPwAn, respectively, but with the opposite sign. A barotropic high-pressure anomaly extends across the northern North Pacific in response to the IPO-associated tropical cold SST 
anomalies.

\section{b. Impact of the AMO}

Both observations (Fig. 2b) and simulations (Fig. 5) suggest that compared with the IPO, the AMO plays an opposite and secondary role in the contrasting precipitation variability between North China and the Southwest US. This finding is also supported

401 by the height response over the northern North Pacific, which is a critical circulation system associated with the seesaw pattern. As clearly shown in Fig. 10, opposite pressure anomalies are associated to the IPO and AMO. In addition, the magnitude of the AMO-induced height anomaly is only approximately one-third to one-half that

405 induced by the IPO, suggesting the IPO plays a dominant role. The IPO-induced height 406 anomaly is intensified when the AMO in the opposite phase (PwAc and PcAw), 407 whereas it is slightly weakened when the AMO in the same phase (PwAw and PcAc). 408

409 AMO on the IPO could be through two pathways: 1) the mid-latitude atmosphere 410 process, the AMO could modify the atmospheric anomalies over Eurasia and further 411 the northern North Pacific via downstream energy propagation at the mid-high

412 latitudes (e.g., Si and Ding, 2016); 2) the tropical atmosphere process, the AMO could 413 generate a trans-basin SLP seesaw, characterized by opposite SLP trends in the 414 Pacific and the Indo-Atlantic region, and further change SST over the eastern tropical 415 Pacific via a modification of the Walker circulation involving low-level wind 416 anomalies (e.g., McGregor et al. 2014). No matter through which pathways, the warm 
417 (cold) AMO phase tends to induce the cold (warm) IPO phase. This is supported that 418 there exists a significant lag anti-correlation between the AMO and the IPO indices 419 with the AMO index leading by approximately 11 12 years (Wu et al. 2011; Chylek et 420 al. 2014).

421 In the CLIVAR AGCMs experiments, the AMO may affect the modulation of the 422 IPO on circulation and precipitation through the first pathway. PnAw (PnAc) drives an 423 eastward-propagating wave train over Eurasia and then, induces a barotropic high 424 (low)-pressure anomaly over the northern North Pacific (Fig. 6 in Yang et al. (2017); 425 also seen Fig. S6 in supplement), which is consistent with the height anomaly associated to $\mathrm{PcAn}(\mathrm{PwAn})$. Consequently, circulation and precipitation responses to

427 PnAw (PnAc) closely resemble those associated with PcAn (PwAn), although with 428 smaller magnitude. When the AMO in combination with the IPO in the opposite phases, 429 PwAc and PcAw (Fig. S7 in supplement), precipitation and circulation responses 430 resemble those in PwAn and PcAn (Fig. 6), respectively, but the strengthened height 431 anomaly over the northern North Pacific is associated with larger anomalies of wind, 432 moisture flux and precipitation (Fig. 11 and Fig. S8 in supplement).

\section{Conclusions and discussion} by idealized IPO- and AMO-associated SST anomalies, we compared the interdecadal

437 precipitation variations over North China and the Southwest US, as well as the 438 associated circulations. Our main findings are summarized as follows: 
440 Southwest US are anti-correlated, implying a seesaw pattern. The IPO could play a

441 dominant role in driving the seesaw pattern, with the warm IPO phase associated with

442 less precipitation over North China but more over the Southwest US; the cold phase is

443 associated with the opposite-signed pattern. The AMO contributes oppositely and less.

444 The IPO-induced precipitation anomaly intensifies when the AMO is in the opposite

445 phase, whereas it is slightly weakened when the AMO in the same phase. The IPO has a

446 much stronger influence on precipitation variations over the Southwest US than that

447 over North China. AGCM simulations from the US CLIVAR Drought Working Group

448 capture these relationships well.

449 Secondly, for the IPO, the large-scale lower-tropospheric cyclonic or anticyclonic

450 circulation anomaly across the northern North Pacific is the predominant factor in

451 driving the seesaw pattern. During the warm IPO phase, North China and the Southwest

452 US, which are located at the western and eastern parts of the deepened Aleutian low,

453 experience anomalous northwesterlies and southwesterlies, and receive below-normal

454 and above-normal precipitation, respectively. Opposite-signed circulation anomalies

455 are associated with the cold IPO phase.

456 Thirdly, the height anomaly over the northern North Pacific, which exhibits an

457 equivalent barotropic structure, is part of the planetary-scale atmospheric response to

458 the IPO-associated tropical SST anomaly. For instance, the warm IPO phase induces a

459 tripole pattern of temperature anomalies over the North Pacific (warm-cold-warm from

460 south to north), that strengthens the mid-latitude meridional temperature gradient but 
461 weakens it in the tropics and high latitudes. By thermal wind balance, these are

462 accompanied by a tripole structure of zonal wind anomaly

463 (easterlies-westerlies-easterlies) that favors a dipole pattern of upper-tropospheric

464 relative vorticity shear, with positive vorticity over the northern North Pacific and

465 negative vorticity to the south. Consequently, a barotropic cyclonic anomaly extends

466 across the northern North Pacific.

467 Given the association between IPO (AMO) phase and interdecadal precipitation

468 variations over North China and the Southwest US, improved prediction of the IPO

469 (AMO) could provide a potential predictability of drought-related water stresses over

470 the two regions, although there are still many uncertainties in our understanding and

471 prediction of these interdecadal oceanic modes. If the phase of the IPO turns positive,

472 as it is projected in late 2014 (Meehl et al. 2016), North China may experience

473 anomalously decreased precipitation, whereas precipitation may enhance across much

474 of North America, including the Southwest US. However, we caution that this analysis

475 considers the IPO and AMO only, and neglects other processes, for instance

476 anthropogenic greenhouse gases and aerosols, which may also induce interdecadal

477 precipitation variability, either through a direct effect on precipitation or an indirect

478 influence on the magnitude or period of the IPO and AMO (e.g., Dong et al. 2014;

479 Smith et al. 2016; Liguori and Di Lorenzo 2018).

480 The observed seesaw pattern is the result of air-sea interactions, although the SST

481 may play a more active role than the atmosphere. However, AGCM simulations used

482 in this study cannot reflect the feedback of the atmosphere to the SST, which may 
lead to erroneous attribution conclusions for decadal-scale circulation and precipitation variability, especially in East Asia (Dong et al. 2017). Additionally, the AGCM simulations show only the steady-state response, which cannot distinguish which circulation feature occurs first in response to the tropical SST anomaly, and thus may cause uncertainty in the potential pathway described here. The Pacific SST forcing (Fig. 1a) used in the AGCM simulations includes a same-signed SST anomaly in the Indian Ocean, which has been shown to contribute to precipitation variations over the US (e.g., Hoerling and Kumer 2003) and North China. The role of the Indian Ocean in the anti-correlation of precipitation over North China and Southwest US is not clear. These issues require further investigation to verify the link between the interdecadal seesaw pattern and the IPO and AMO.

Acknowledgments This study is jointly sponsored by the National Key R\&D Program of China (2016YFA0600404), the National Natural Science Foundation of China (41530532, 41705073), the China Special Fund for Meteorological Research in the Public Interest (GYHY201106028, GYHY201506001-1), and the Jiangsu Collaborative Innovation Center for Climate Change. Nicholas P. Klingaman was funded by an Independent Research Fellowship from the UK Natural Environment Research Council (NE/L010976/1). Peili Wu was supported by the UK-China Research and Innovation Partnership Fund through the Met Office Climate Science for Services Partnership (CSSP), as part of the Newton Fund. 


\section{References}

506 Bacmeister, J., P. J. Pegion, S. D. Schubert, and M. J. Suarez, 2000: An Atlas of Seasonal Means Simulated by the NSIPP 1 Atmospheric GCM. NASA Tech. Memo. 104606, Vol. 17, Goddard Space Flight Center, 194 pp.

Campana, K., and P. Caplan, Eds., 2005: Technical procedure bulletin for the T382 Global Forecast System. NOAA/NCEP/EMC.

511 Chen, H., T. Zhou, R. B. Neale, X. Wu and G. J. Zhang, 2010: Performance of the New NCAR CAM3.5 in East Asian Summer Monsoon Simulations: Sensitivity to

Dai, A., 2011: Characteristics and trends in various forms of the Palmer Drought 10.1175/2010JCLI3022.1.

Chylek, P., M. K. Dubey, G. Lesins, J. N. Li and N. Hengartner. 2014: Imprint of the Atlantic multi-decadal oscillation and Pacific decadal oscillation on southwestern US climate: past, present, and future. Climate Dynamics, 43, 119-129. Severity Index during 1900-2008. J. Geophys. Res. 116, D12115.

Dai, A., 2013: The influence of the inter-decadal Pacific oscillation on US precipitation during 1923-2010. Clim. Dyn., 41, 633-646, doi:10.1007/s00382-012-1446-5.

Delworth, T. L., and Coauthors, 2006: GFDL's CM2 global coupled climate models. Part I: Formulation and simulation characteristics. J. Climate, 19, 643-674, doi:10.1175/JCLI3629.1.

Di Lorenzo, E., G. Liguori, N. Schneider, J. C. Furtado, B. T. Anderson, and M. A. Alexander, 2015: ENSO and meridional modes: A null hypothesis for Pacific 
Dong, B., and A. Dai, 2015: The influence of the Interdecadal Pacific Oscillation on Temperature and Precipitation over the Globe. Climate Dynamics, 45, 2667-2681.

Dong, B., Sutton, R.T., Shaffrey, L. and Klingaman, N. P., 2017: Attribution of Forced Decadal Climate Change in Coupled and Uncoupled Ocean-Atmosphere Model Experiments. J. Climate, 30 6203-6223.

Dong, L., T. Zhou, and X. Chen, 2014: Changes of Pacific decadal variability in the twentieth century driven by internal variability, greenhouse gases, and aerosols. Geophysical Research Letters, 41, 8570-8577.

Enfield, D. B., A. M. Mestas-Nunez, and P. J. Trimble, 2001: The Atlantic Multidecadal Oscillation and its relationship to precipitation and river flows in the continental U.S. Geophys. Res. Lett., 28: 2077-2080.

Fang, K., D. Chen, J. Li, and H. Seppä, 2014: Covarying Hydroclimate Patterns between Monsoonal Asia and North America over the Past 600 Years. Journal of Climate, 27, 8017-8033.

Fang, K., H. Seppä, and D. Chen, 2015: Interdecadal hydroclimate teleconnections between Asia and North America over the past 600 years. Climate Dynamics, 44,

Farneti, R., F. Molteni, and F. Kucharski, 2014: Pacific interdecadal variability driven $1777-1787$.

547 Feng, S., Q. Hu and R. J. Oglesby, 2011: Influence of Atlantic sea surface temperatures on persistent drought in North America. Climate Dyn., 37, 569-586, 
doi:10.1007/s00382-010-0835-x.

550 Henley, B. J., 2017: Pacific decadal climate variability: Indices, patterns and tropical-extratropical interactions. Global and Planetary Change, 155, 42-55.

552 Henley, B. J., and Coauthors, 2017: Spatial and temporal agreement in climate model 553 simulations of the Interdecadal Pacific Oscillation. Environmental Research $554 \quad$ Letters, 12.

555 Hoerling, M. and Kumar, A., 2003: The perfect ocean for drought. Science, 299, 691-4. 556 Hua, L., Z. Ma and L. Zhong, 2011: A comparative analysis of primary and extreme 557 characteristics of dry or wet status between Asia and North America. Adv. Atmos. Sci., 28, 352-362.

Huang, B., and Coauthors, 2015: Extended Reconstructed Sea Surface Temperature Version 4 (ERSST.v4). Part I: Upgrades and Intercomparisons. Journal of Climate, 28, 911-930.

562 Huang, J., and Coauthors, 2017: Dryland climate change: Recent progress and challenges. Reviews of Geophysics, 55, 719-778.

564 Hu, Q., S. Feng, and R. J. Oglesby, 2011: Variations in North American Summer 565 Precipitation Driven by the Atlantic Multidecadal Oscillation. J. Climate, 24,

567 Kalnay, E., and Coauthors, 1996: The NCEP/NCAR 40-Year Reanalysis Project. Bull. 568 Amer. Meteor. Soc., 77, 437-471, doi:10.1175/1520-0477(1996)077,0437:TNYRP.2.0.CO;2.

570 Kang, S., and E. A. B. Eltahir, 2018: North China Plain threatened by deadly 
572 Kerr, R. A., 2000: A north Atlantic climate pacemaker for the centuries. Science, 288, 1984-1986. doi:10.1126/science.288.5473.1984.

574 Kiehl, J. T., J. J. Hack, G. B. Bonan, B. A. Boville, D. L. Williamson and P. J. Rasch, 1998: The National Center for Atmospheric Research Community Climate Model: CCM3. J. Climate, 11, 1131-1149,

Lau, K., and H. Weng, 2002: Recurrent teleconnection patterns linking summertime doi:10.1175/1520-0442(1998)011<1131:TNCFAR>2.0.CO;2. precipitation variability over East Asia and North America. Journal of the Meteorological Society of Japan, 80, 1309-1324.

581 Lau, K., J. Lee, K. Kim, and I. Kang, 2004: The North Pacific as a Regulator of Summertime Climate over Eurasia and North America. Journal of Climate, 17, 819-833.

Li, H., A. Dai, T. Zhou and J. Lu, 2010: Responses of East Asian summer monsoon to historical SST and atmospheric forcing during 1950-2000. Climate Dyn., 34, 501-514, doi: 10.1007/s00382-008-0482-7.

Li, Q., S. Yang, V. E. Kousky, R. W. Higgins, K. M. Lau, and P. Xie, 2005: Features of cross-Pacific climate shown in the variability of China and US precipitation. International Journal of Climatology, 25, 1675-1696.

590 Li, S., and G. T. Bates, 2007: Influence of the Atlantic multidecadal oscillation on the $591 \quad$ winter climate of East China. Adv. Atmos. Sci., 24, 126-135, 592 doi:10.1007/s00376-007-0126-6. 
Liguori, G., and E. Di Lorenzo, 2018: Meridional Modes and Increasing Pacific Decadal Variability Under Anthropogenic Forcing. Geophysical Research

$$
\text { Letters, 45, 983-991. }
$$

Lu, R., B. Dong, and H. Ding, 2006: Impact of the Atlantic Multidecadal Oscillation on the Asian summer monsoon. Geophysical Research Letters, 33, L24701.

Ma, Z., 2007: The interdecadal trend and shift of dry/wet over the central part of North China and their relationship to the Pacific Decadal Oscillation (PDO). Chin. Sci. Bull., 52, 2130-2139, doi: 10.1007/s11434-007-0284-z.

Ma, Z. and C. Fu, 2007: Evidences of Drying Trend in the Global During the later Half of 20th Century and Their Relationship with Large-Scale Climate Background. Sci. China Ser. D-Earth Sci., 50, 776-788.

Ma, Z. and L. Shao, 2006: Relationship Between Dry/Wet Variation and the Pacific Decade Oscillation (PDO) in Northern China During the Last 100 Years. Chinese Journal of Atmospheric Sciences, 30, 464-474. (in Chinese)

McCabe, G. J., M. A. Palecki, and J. L. Betancourt, 2004: Pacific and Atlantic Ocean influences on multidecadal drought frequency in the United States. Proc Natl Acad Sci USA, 101, 4136-4141.

McGregor, S., A. Timmermann, M. F. Stuecker, M. H. England, M. Merrifield, F.-F. Jin, and Y. Chikamoto, 2014: Recent Walker circulation strengthening and Pacific cooling amplified by Atlantic warming. Nature Climate Change, 4, 888-892.

Mantua, N. J., S. R. Hare, Y. Zhang, J. M. Wallace and R. C. Francis, 1997: A Pacific interdecadal climate oscillation with impacts on salmon production. Bull. Amer. 
Meteor. Soc., 78, 1069-1079,

doi:10.1175/1520-0477(1997)078<1069:APICOW>2.0.CO;2.

Mantua, N. J. and S. R. Hare, 2002: The Pacific decadal oscillation. J. Oceanogr., 58, 35-44, doi: 10.1023/A:1015820616384.

Meehl, G. A., and A. Hu, 2006: Megadroughts in the Indian Monsoon Region and Southwest North America and a Mechanism for Associated Multidecadal Pacific Sea Surface Temperature Anomalies. J. Climate, 19, 1605-1623.

Meehl, G. A., A. Hu, and H. Teng, 2016: Initialized decadal prediction for transition to positive phase of the Interdecadal Pacific Oscillation. Nat Commun, 7, 11718.

Mo, K. C., J.-K. E. Schemm and S.-H. Yoo, 2009: Influence of ENSO and the Atlantic Multidecadal Oscillation on Drought over the United States. J. Climate, 22, 5962-5982, doi:10.1175/2009JCLI2966.1.

Newman, M., and Coauthors, 2016: The Pacific Decadal Oscillation, Revisited. Journal of Climate, 29, 4399-4427.

Power, S., T. Casey, C. Folland, A. Colman, and V. Mehta, 1999: Inter-decadal modulation of the impact of ENSO on Australia. Climate Dyn., 15, 319-324, doi: $10.1007 / \mathrm{s} 003820050284$.

Qian, C. and T. Zhou, 2014: Multidecadal Variability of North China Aridity and Its Relationship to PDO during 1900-2010. J. Climate, 27, 1210-1222, doi:10.1175/JCLI-D-13-00235.1.

Rayner, N. A., D. E. Parker, E. B. Horton, C. K. Folland, L. V. Alexander, D. P. Rowell, E. C. Kent and A. Kaplan, 2003: Global analyses of sea surface temperature, sea 

Res. Atmos., 108, 4407, doi:10.1029/2002JD002670.

639

Rowell, D. P., 1998: Assessing potential seasonal predictability with an ensemble of multidecadal GCM simulations. J. Climate, 11, 109-120, doi:10.1175/1520-0442(1998)011<0109:APSPWA>2.0.CO;2.

Schubert, S., et al., 2009: A US CLIVAR Project to Assess and Compare the Responses of Global Climate Models to Drought-Related SST Forcing Patterns: Overview and Results. J. Climate, 22, 5251-5272, doi:10.1175/2009JCLI3060.1.

Seager, R., Harnik, N. and Kushnir, Y., 2003: Mechanisms of Hemispherically Symmetric Climate Variability. J. Climate, 16, 2960-2978, doi: 10.1175/1520-0442(2003)016<2960:MOHSCV>2.0.CO;2.

Si, D., and Y. Ding, 2016: Oceanic forcings of the interdecadal variability in East Asian summer rainfall. J. Climate, 29, 7633-7649, doi:10.1175/JCLI-D-15-0792.1.

Si, D., and A. Hu, 2017: Internally Generated and Externally Forced Multidecadal Oceanic Modes and Their Influence on the Summer Rainfall over East Asia. Journal of Climate, 30, 8299-8316.

Smith, D. M., and Coauthors, 2016: Role of volcanic and anthropogenic aerosols in the recent global surface warming slowdown. Nature Climate Change, $\mathbf{6}$, 936-940.

Sutton, R. T., and D. L. Hodson, 2005: Atlantic Ocean forcing of North American and European summer climate. Science, 309, 115-118.

Sutton, R. T., and D. L. Hodson, 2007: Climate Response to Basin-Scale Warming and 
660 University of East Anglia Climatic Research Unit, I. C. Harris, P. D. Jones, 2017: CRU

661 TS4.00: Climatic Research Unit (CRU) Time-Series (TS) version 4.00 of high

662 resolution gridded data of month-by-month variation in climate (Jan. 1901- Dec.

663 2015). Centre for Environmental Data Analysis, 25 August 2017,

664 doi:10.5285/edf8febfdaad48abb2cbaf7d7e846a86.

665 Vellinga, M. and P. Wu, 2004: Low-latitude freshwater influence on centennial

666 variability of the thermohaline circulation. J. Climate, 17, 4498-4511.

667 Wang, B., Q. H. Ding, X. H. Fu, I. S. Kang, K. Jin, J. Shukla and F. Doblas-Reyes, 2005:

668 Fundamental challenge in simulation and prediction of summer monsoon

669 precipitation. Geophys. Res. Lett., 32, L15711, doi:10.1029/2005GL022734.

670 Wang, F., S. Yang, W. Higgins, Q. Li, and Z. Zuo, 2014: Long-term changes in total

671 and extreme precipitation over China and the United States and their links to

672 oceanic-atmospheric features. International Journal of Climatology, 34, 286-302.

673 Wu, P., N. Christidis and P. Stott, 2013: Anthropogenic impact on Earth's hydrological

$674 \quad$ cycle. Nature Climate Change, 3, 807-810.

675 Wu, P., J. Ridley, A. Pardaens, R. Leavine and J. Lowe, 2015: The reversibility of CO2

676 induced climate change. Clim. Dyn., 45, pp745-754.

677 Wu, R. and Kirtman, B.P., 2007. Regimes of seasonal air-sea interaction and

678 implications for performance of forced simulations. Climate Dynamics, 29,

$679 \quad 393-410$.

680 Wu, S., Z. Liu, R. Zhang, and T. L. Delworth, 2011: On the observed relationship 
Wilks, D.S., 2005: Statistical methods in the atmospheric sciences: second edition. International Geophysics Series, 138:140.

Yang, L., and Z. Fu, 2016: Out-phased decadal precipitation regime shift in China and 686 the United States. Theoretical and Applied Climatology, 130, 535-544.

Yang, Q., Z. Ma, and B. Xu, 2016: Modulation of monthly precipitation patterns over 688 East China by the Pacific Decadal Oscillation. Climatic Change, 144, 405-417. Precipitation Patterns over Eastern China by Sea Surface Temperature Anomalies. Journal of Climate, 30, 7017-7033.

692 Zhang, L., P. Wu, T. Zhou 2017: Aerosol Forcing of Extreme Summer Drought over North China. Environ. Res. Lett., 12,034020.

694 Zhang, Y., J. M. Wallace, and D. S. Battisti, 1997: ENSO-like interdecadal variability: 695 1900-93. J. Climate, 10, 1004-1020,

697 Zhao, P., S. Yang, H. Wang, and Q. Zhang, 2011: Interdecadal Relationships between 698 the Asian-Pacific Oscillation and Summer Climate Anomalies over Asia, North 699 Pacific, and North America during a Recent 100 Years. Journal of Climate, 24, 4793-4799. 
701 Zhao, P., and Coauthors, 2016: Summer precipitation anomalies in Asia and North 702 America induced by Eurasian non-monsoon land heating versus ENSO. Sci Rep, 6, $703 \quad 21346$

704 Zhou, T., F. Song, R. Lin, X. Chen and X. Chen, 2013: The 2012 North China floods: 705 explaining an extreme precipitation event in the context of a longer-term drying 706 tendency [in "Explaining Extreme Events of 2012 from a Climate Perspective"]. 707 Bull. Amer. Meteor. Soc., 94, S49-S51, doi:10.1175/BAMS-D-13-00085.1.

708 Zhu, Y., H. Wang, W. Zhou and J. Ma, 2011: Recent changes in the summer 709 precipitation pattern in East China and the background circulation. Climate Dyn., $710 \quad 36,1463-1473$, doi: 10.1007/s00382-010-0852-9.

711 Zhu, Y., H. Wang, J. Ma, T. Wang, and J. Sun, 2015: Contribution of the phase 712 transition of Pacific Decadal Oscillation to the late 1990s' shift in East China 713 summer precipitation. Journal of Geophysical Research: Atmospheres, 120, $714 \quad 8817-8827$.

715 Zhu, Y., T. Wang and J. Ma, 2016: Influence of internal decadal variability on the 716 summer precipitation in Eastern China as simulated by CCSM4. Adv. Atmos. Sci., 717 33, 706-714, doi: 10.1007/s00376-016-5269-x.

718 Zhu, Z., and T. Li, 2016: A New Paradigm for Continental U.S. Summer Rainfall 719 Variability: Asia-North America Teleconnection. Journal of Climate, 29, $720 \quad 7313-7327$. 


\section{Table Caption List}

2 Table 1. The combinations of Pacific and Atlantic SST anomaly patterns used to force

3 the AGCMs. Here $w$ refers to the warm phase of the pattern (scaled by $+2 \sigma), n$ denotes

4 neutral (zero anomaly), and $c$ refers to the cold phase (scaled by $-2 \sigma$ ). The PnAn

5 experiment denotes the control run forced with the annually varying climatological

$6 \quad$ SST (Schubert et al. 2009).

7

Figure Caption List

9 Fig. 1 The second and third leading REOFs $\left({ }^{\circ} \mathrm{C}\right)$ and associated time-series RPCs $\left({ }^{\circ} \mathrm{C}\right)$

10 of annual mean SST from 1901 to 2004 (Schubert et al. 2009). (a) The Pacific

11 ENSO-like SSTA pattern of REOF2 and (b) associated RPC2 and the IPO index. (c)

12 The Atlantic AMO SSTA pattern of REOF3 and (d) associated RPC3 and AMO index.

13 The blue curves ( $b$ and $d$ ) are smoothed time series obtained by applying a 9-year

14 moving average twice to the bars to emphasize the interdecadal variations. The same

15 method is applied to the IPO and AMO indices. $r$ and $p$ represent the correlation

16 coeffients between red and blue curves, and the statistical significance level,

17 respectively. The percentages indicate the corresponding explained variances.

19 Fig. 2 (a) Detrended monthly precipitation anomalies over North China $\left(110^{\circ} \mathrm{E} \sim 118^{\circ} \mathrm{E}\right.$,

$\left.2034^{\circ} \mathrm{N} \sim 42.5^{\circ} \mathrm{N}\right)$ and the Southwest US $\left(105^{\circ} \mathrm{W} \sim 120^{\circ} \mathrm{W}, 30^{\circ} \mathrm{N} \sim 40^{\circ} \mathrm{N}\right)$ and the IPO and

21 AMO indices, obtained by applying a 109-month moving average twice. Observed

22 precipitation anomalies over North China are referred to as "North China_station". 
Black dotted lines represent $\pm 0.5 \sigma$ of the IPO index. (b) Annual mean precipitation anomaly percentage (\%) over North China and the Southwest US during different periods: cold IPO (IPO-), cold IPO plus warm AMO (IPO-AMO+), cold IPO plus cold AMO (IPO-AMO-), warm IPO (IPO+), warm IPO plus cold AMO (IPO+AMO-), and warm IPO plus warm AMO (IPO+AMO+), with respect to the climatology from 1920 to 2014. Statistically significant anomalies at the 5\% level are indicated by black triangles.

Fig. 3 The IPO phase composite anomaly (relative to 1900-2014) maps of the detrended precipitation $\left(\mathrm{mm} \mathrm{day}^{-1}\right)$ over North China (left column) and the Southwest US (middle column), and annual mean SST $\left({ }^{\circ} \mathrm{C}\right.$, right column) for the cold ( $\mathrm{a}, \mathrm{b}$, and $\mathrm{c}$, 1947-1972; g, h, and i, 2003-2014) and warm epoches (d, e, and f, 1977-1998), respectively. The boundaries of North China and the Southwest US are outlined in blue boxes. The dotted areas represent statistically significant anomalies at the 5\% level.

Fig. 4 Regression maps of the detrended monthly (a) (b) SST $\left({ }^{\circ} \mathrm{C}\right.$, shaded) and SLP (hPa, contours), (c) (d) $200 \mathrm{hPa}$ geopotential height ( $\mathrm{Z}, \mathrm{m}$, contours) and $850 \mathrm{hPa}$ wind (UV, $\mathrm{m} \mathrm{s}^{-1}$, vector) regressed onto the detrended monthly precipitation anomalies over North China and the Southwest US. The SST, circulation variables and precipitation are smoothed by applying a 109-month moving average twice. Only statistically significant $(p<0.05)$ regression coefficients of $850 \mathrm{hPa}$ wind are illustrated. The dotted and shaded areas represent significant $(p<0.05)$ regression coefficients of 
SST and $200 \mathrm{hPa}$ geopotential height, repectively.

Fig. 5 Multi-model ensemble mean anomalies of annual and seasonal precipitation $\left(m m\right.$ day $\left.^{-1}\right)$ over (a) North China and (b) the Southwest US relative to the control run (PnAn). Error bars indicate the intermodel range. Here, $\mathrm{P}$ and A denote the Pacific (IPO) and Atlantic (AMO) SST anomaly patterns; $w, n$ and $c$ refer to the warm, neutral and cold phases, respectively (Table 1).

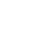

Fig. 6 Multi-model ensemble mean anomalies of annual mean (a) (b) SLP (hPa, shaded) and its climatology in PnAn (hPa, contours); (c) (d) 500-hPa geopotential height (Z, m, shaded) and $850 \mathrm{hPa}$ wind (UV, $\mathrm{m} \mathrm{s}^{-1}$, vectors); (e) (f) column-integrated moisture divergence (mm day ${ }^{-1}$, shaded) and moisture flux $\left(\mathrm{g} \mathrm{cm}^{-1} \mathrm{~s}^{-1}\right.$, vectors); (g) (h) precipitation (Pre, mm day ${ }^{-1}$, shaded), for PwAn (left column) and PcAn (right column). Note that an unequal contour interval is used to highlight the response over land. Stippling indicates areas where more than four of the five AGCMs agree on the sign.

Fig. 7 Multi-model ensemble mean anomalies of annual mean (a) (b) air temperature (T, from surface to $200 \mathrm{hPa}$, contours, $\mathrm{K}$ ) and $200 \mathrm{hPa}$ zonal wind ( $\mathrm{U}$, shaded, $\mathrm{m} \mathrm{s}^{-1}$ ); wind (UV, $\mathrm{m} \mathrm{s}^{-1}$, vectors) and relative vorticity (scaled by 1e5, $\mathrm{s}^{-1}$, shaded) at (c) (d) $200 \mathrm{hPa}$, and (e) (f) $850 \mathrm{hPa}$; (g) (h) meridional (V, $\mathrm{m} \mathrm{s}^{-1}$, vectors) and vertical (W, $10^{-3} \mathrm{~m} \mathrm{~s}^{-1}$, shaded) circulation, and (i) (j) SST (scaled by $2,{ }^{\circ} \mathrm{C}$ ) and precipitation (Pre, $\mathrm{mm} \mathrm{day}^{-1}$ ) over the Pacific (average $150^{\circ} \mathrm{E} \sim 120^{\circ} \mathrm{W}$ ), for PwAn (left column) and PcAn (right 
column). For convenience in comparing quantitatively the precipitation responses in different experiments, the zonal-mean precipitation anomalies in experiments with the warm (Pw) and cold IPO (Pc), as well as PnAc and PnAw, are illustrated in (i) and (j), respectively.

Fig. 8 Anomalies of annual mean (a) (b) air temperature (T, from surface to $200 \mathrm{hPa}$, contours, $\mathrm{K})$ and $200 \mathrm{hPa}$ zonal wind (U, shaded, $\left.\mathrm{m} \mathrm{s}^{-1}\right)$; wind (UV, $\mathrm{m} \mathrm{s}^{-1}$, vectors) and relative vorticity (scaled by 1e5, $\mathrm{s}^{-1}$, shaded) at (c) (d) $200 \mathrm{hPa}$, and (e) (f) $850 \mathrm{hPa}$ for TPwAn in GFDL (left column) and NSIPP1 (right column).

(1)

Fig. 9 Responses of annual mean precipitation $\left(\mathrm{mm} \mathrm{day}^{-1}\right.$, shaded) to the Pacific pattern (PwAn and PcAn) and its tropical SST component (TPwAn and TPcAn) in GFDL. The dotted areas represent statistically significant anomalies at the $5 \%$ level.

Fig. 10 Multi-model ensemble mean anomalies of annual mean geopotential height (m) over the northern North Pacific $\left(30^{\circ}-65^{\circ} \mathrm{N}, 160^{\circ} \mathrm{E}-140^{\circ} \mathrm{W}\right)$ from surface to $70 \mathrm{hPa}$.

Fig. 11 Left column: Multi-model ensemble mean differences between PwAc and

$$
\text { PwAn: (a) SLP (hPa, shaded) and SLP climatology in PwAn (hPa, contours); (c) } 500
$$

$\mathrm{hPa}$ geopotential height ( $\mathrm{Z}, \mathrm{m}$, shaded) and $850 \mathrm{hPa}$ wind (UV, $\mathrm{m} \mathrm{s}^{-1}$, vectors); (e)

7 column-integrated moisture divergence $\left(\mathrm{mm} \mathrm{day}^{-1}\right.$, shaded $)$ and moisture flux $\left(\mathrm{g} \mathrm{cm}^{-1}\right.$

$\mathrm{s}^{-1}$, vectors); (g) precipitation (Pre, $\mathrm{mm} \mathrm{day}^{-1}$, shaded). Right column is the same as left 
one, but for differences between PcAw and PcAn.

90

91 Tables

92 Table 1. The combinations of Pacific and Atlantic SST anomaly patterns used to force

93 the AGCMs. Here $w$ refers to the warm phase of the pattern (scaled by $+2 \sigma), n$ denotes

94 neutral (zero anomaly), and $c$ refers to the cold phase (scaled by $-2 \sigma$ ). The PnAn

95 experiment denotes the control run forced with the annually varying climatological 96 SST (Schubert et al. 2009).

\begin{tabular}{lccc}
\hline & Warm & Neutral & Cold \\
& Atlantic & Atlantic & Atlantic \\
\hline Warm Pacific & PwAw & PwAn & PwAc \\
Neutral Pacific & PnAw & PnAn & PnAc \\
Cold Pacific & PcAw & PcAn & PcAc \\
Warm tropical Pacific & - & TPwAn & - \\
Cold tropical Pacific & - & TPcAn & - \\
\hline
\end{tabular}

97 

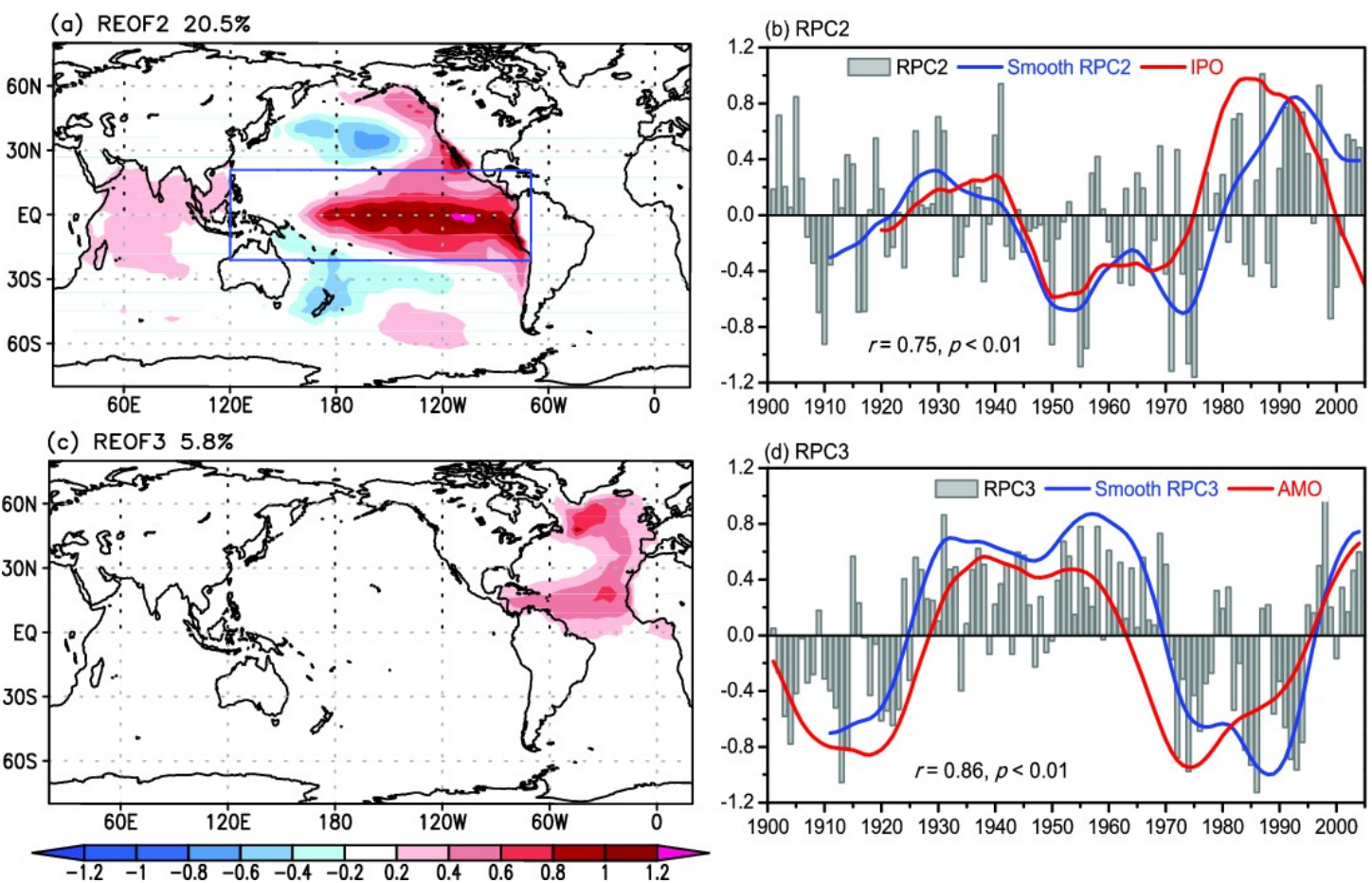

Fig. 1 The second and third leading REOFs $\left({ }^{\circ} \mathrm{C}\right)$ and associated time-series RPCs $\left({ }^{\circ} \mathrm{C}\right)$ of annual mean SST from 1901 to 2004 (Schubert et al. 2009). (a) The Pacific

102 ENSO-like SSTA pattern of REOF2 and (b) associated RPC2 and the IPO index. (c)

103 The Atlantic AMO SSTA pattern of REOF3 and (d) associated RPC3 and AMO index.

104 The blue curves ( $b$ and $d$ ) are smoothed time series obtained by applying a 9-year

105 moving average twice to the bars to emphasize the interdecadal variations. The same method is applied to the IPO and AMO indices. $r$ and $p$ represent the correlation coeffients between red and blue curves, and the statistical significance level, respectively. The percentages indicate the corresponding explained variances. 

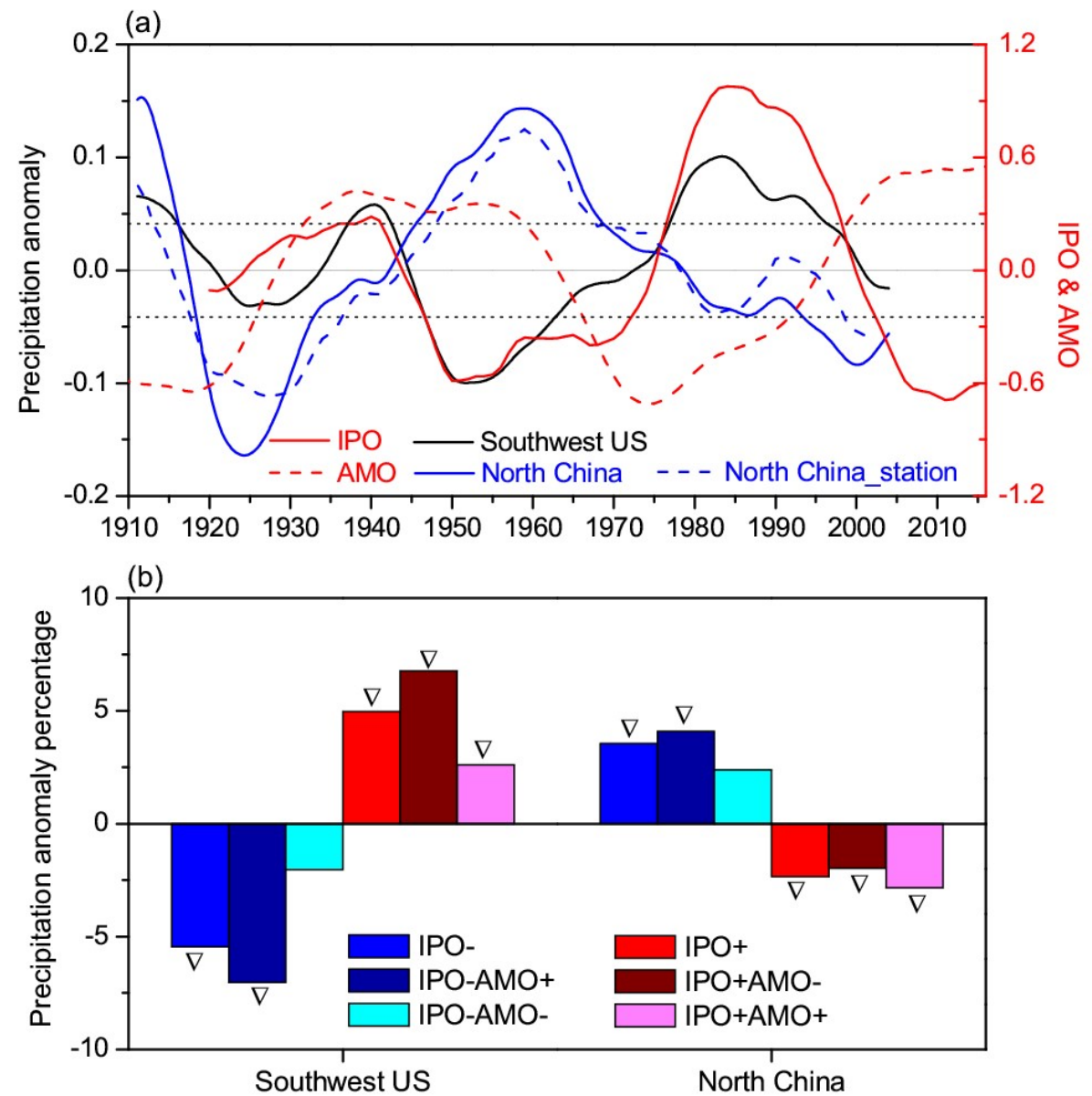

110 Fig. 2 (a) Detrended monthly precipitation anomalies over North China $\left(110^{\circ} \mathrm{E} \sim 118^{\circ} \mathrm{E}\right.$,

$\left.11134^{\circ} \mathrm{N} \sim 42.5^{\circ} \mathrm{N}\right)$ and the Southwest US $\left(105^{\circ} \mathrm{W} \sim 120^{\circ} \mathrm{W}, 30^{\circ} \mathrm{N} \sim 40^{\circ} \mathrm{N}\right)$ and the IPO and

112 AMO indices, obtained by applying a 109-month moving average twice. Observed

113 precipitation anomalies over North China are referred to as "North China_station".

114 Black dotted lines represent $\pm 0.5 \sigma$ of the IPO index. (b) Annual mean precipitation

115 anomaly percentage (\%) over North China and the Southwest US during different

116 periods: cold IPO (IPO-), cold IPO plus warm AMO (IPO-AMO+), cold IPO plus cold

117 AMO (IPO-AMO-), warm IPO (IPO+), warm IPO plus cold AMO (IPO+AMO-), and

118 warm IPO plus warm AMO (IPO+AMO+), with respect to the climatology from 1920

119 to 2014. Statistically significant anomalies at the 5\% level are indicated by black triangles. 

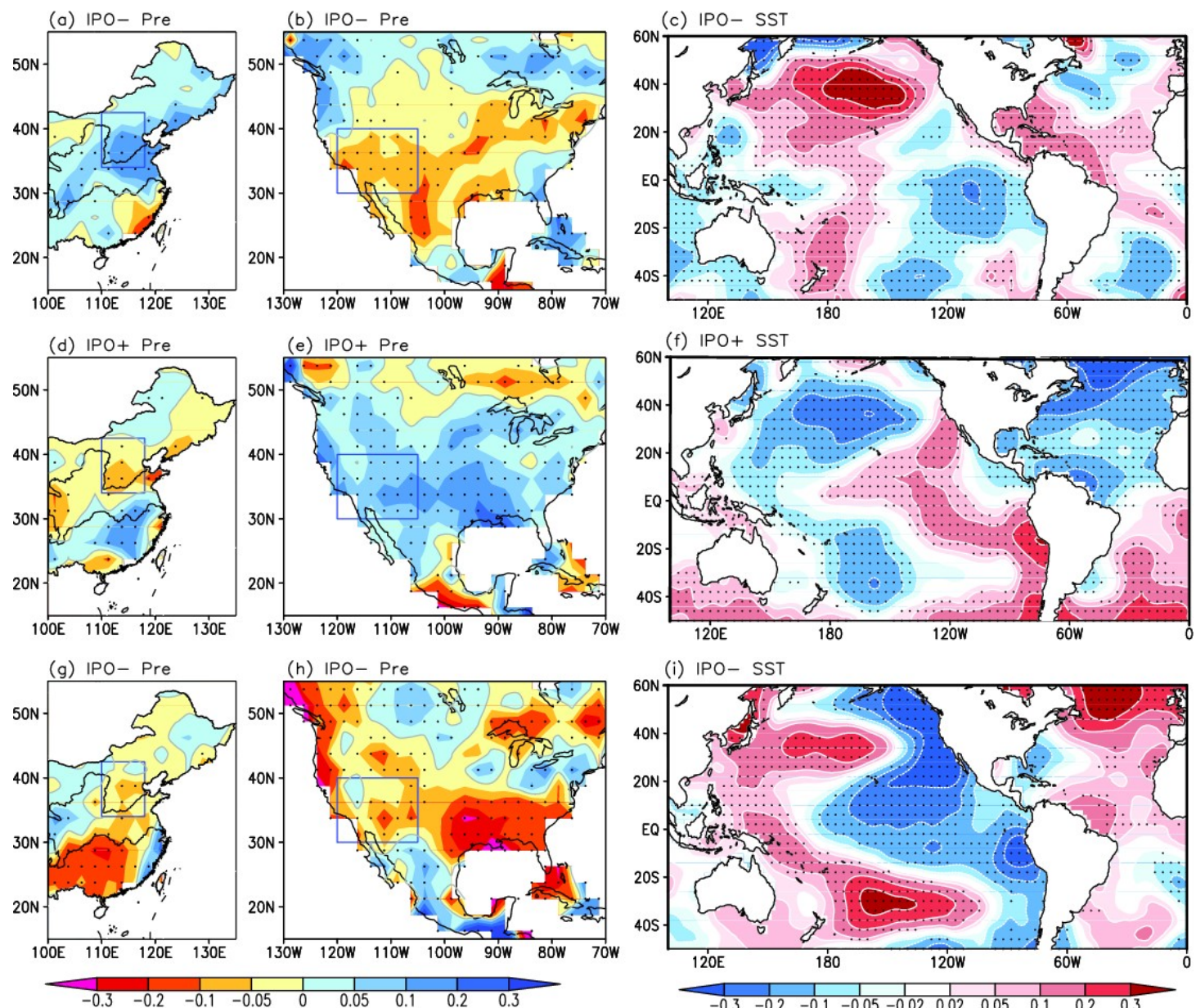

Fig. 3 The IPO phase composite anomaly (relative to 1900-2014) maps of the

125 detrended precipitation ( $\mathrm{mm} \mathrm{day}^{-1}$ ) over North China (left column) and the Southwest

126 US (middle column), and annual mean SST $\left({ }^{\circ} \mathrm{C}\right.$, right column) for the cold (a, b, and c,

1947-1972; g, h, and i, 2003-2014) and warm epoches (d, e, and f, 1977-1998),

128 respectively. The boundaries of North China and the Southwest US are outlined in blue boxes. The dotted areas represent statistically significant anomalies at the 5\% level. 

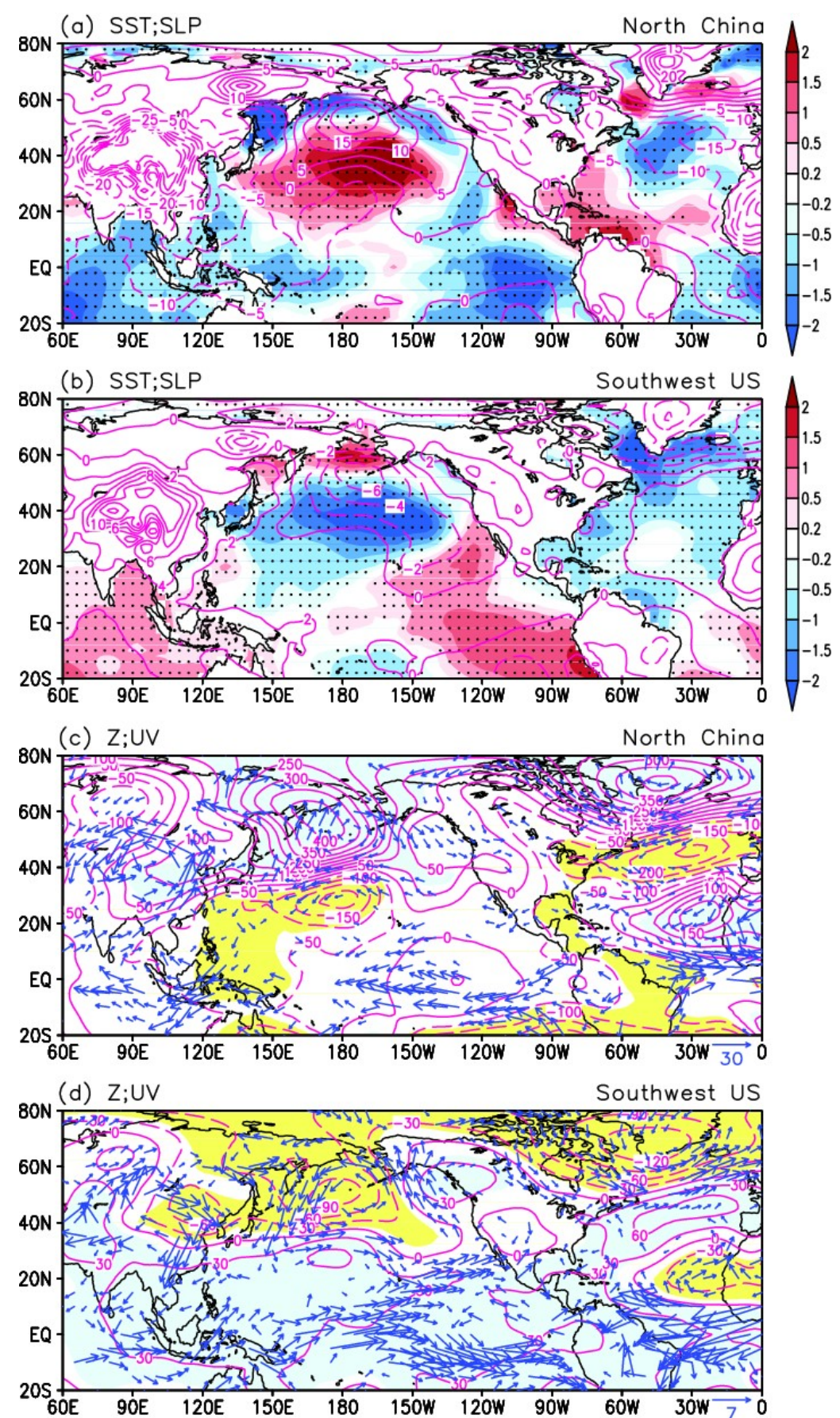

Fig. 4 Regression maps of the detrended monthly (a) (b) SST $\left({ }^{\circ} \mathrm{C}\right.$, shaded) and SLP

133 (hPa, contours), (c) (d) $200 \mathrm{hPa}$ geopotential height (Z, m, contours) and $850 \mathrm{hPa}$

134 wind ( $\mathrm{UV}, \mathrm{m} \mathrm{s}^{-1}$, vector) regressed onto the detrended monthly precipitation anomalies over North China and the Southwest US. The SST, circulation variables and 136 precipitation are smoothed by applying a 109-month moving average twice. Only

137 statistically significant $(p<0.05)$ regression coefficients of $850 \mathrm{hPa}$ wind are illustrated.

138 The dotted and shaded areas represent significant $(p<0.05)$ regression coefficients of 
(a) North China

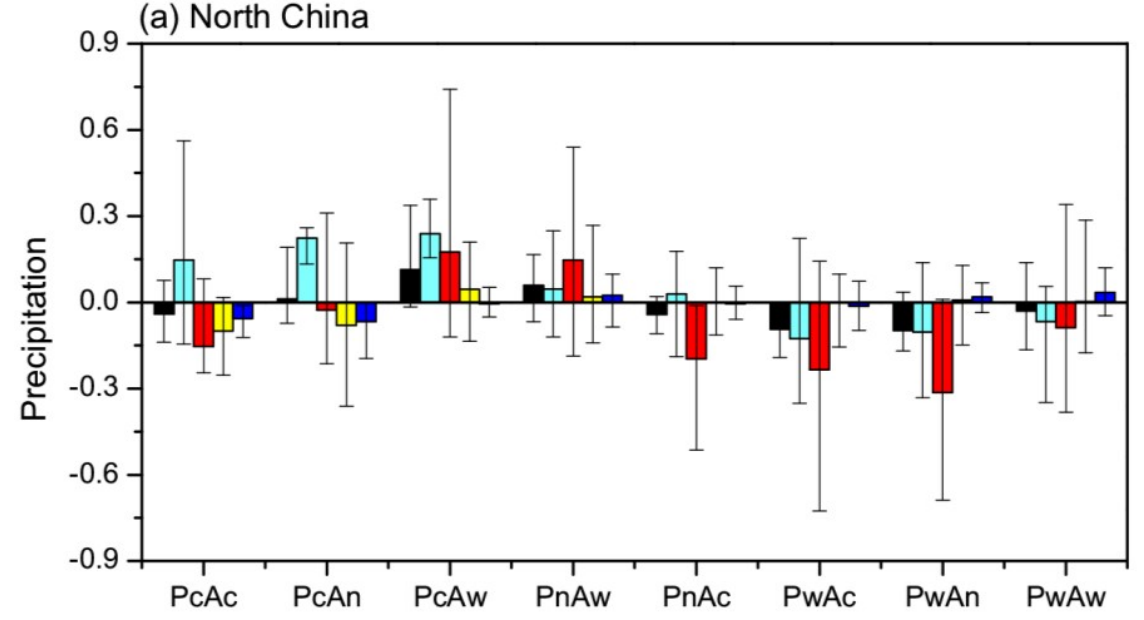

(b) Southwest US

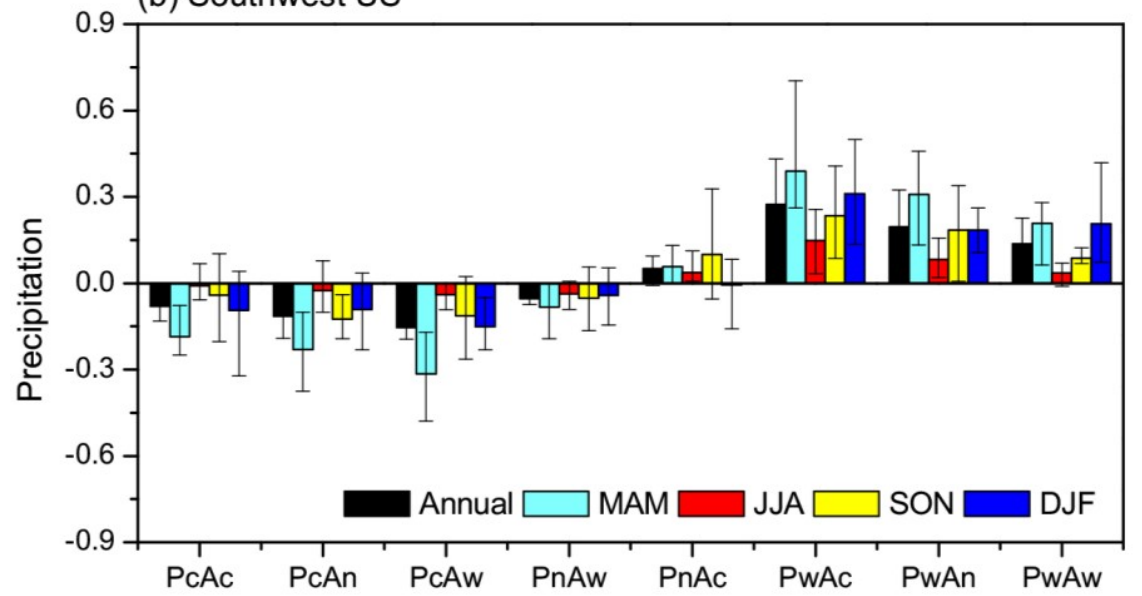

Fig. 5 Multi-model ensemble mean anomalies of annual and seasonal precipitation

142 (mm day ${ }^{-1}$ ) over (a) North China and (b) the Southwest US relative to the control run

143 (PnAn). Error bars indicate the intermodel range. Here, P and A denote the Pacific

144 (IPO) and Atlantic (AMO) SST anomaly patterns; $w, n$ and $c$ refer to the warm,

145 neutral and cold phases, respectively (Table 1). 

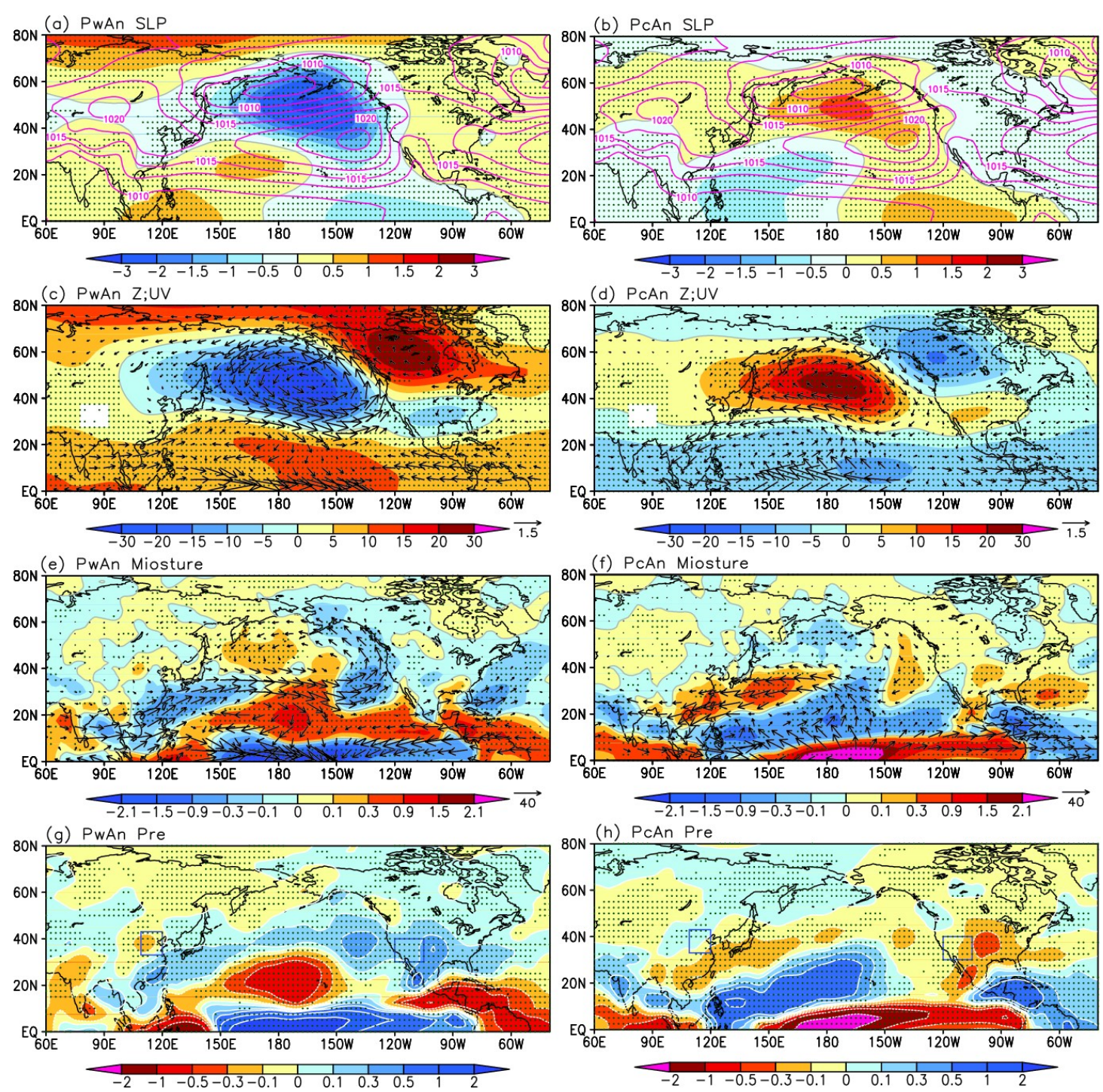

148 Fig. 6 Multi-model ensemble mean anomalies of annual mean (a) (b) SLP (hPa, shaded)

149 and its climatology in PnAn (hPa, contours); (c) (d) 500-hPa geopotential height (Z, m,

150 shaded) and $850 \mathrm{hPa}$ wind (UV, $\mathrm{m} \mathrm{s}^{-1}$, vectors); (e) (f) column-integrated moisture

151 divergence $\left(\mathrm{mm}^{-1 a y}{ }^{-1}\right.$, shaded) and moisture flux $\left(\mathrm{g} \mathrm{cm}^{-1} \mathrm{~s}^{-1}\right.$, vectors); $(\mathrm{g})(\mathrm{h})$

152 precipitation (Pre, mm day ${ }^{-1}$, shaded), for PwAn (left column) and PcAn (right column).

153 Note that an unequal contour interval is used to highlight the response over land.

154 Stippling indicates areas where more than four of the five AGCMs agree on the sign. 

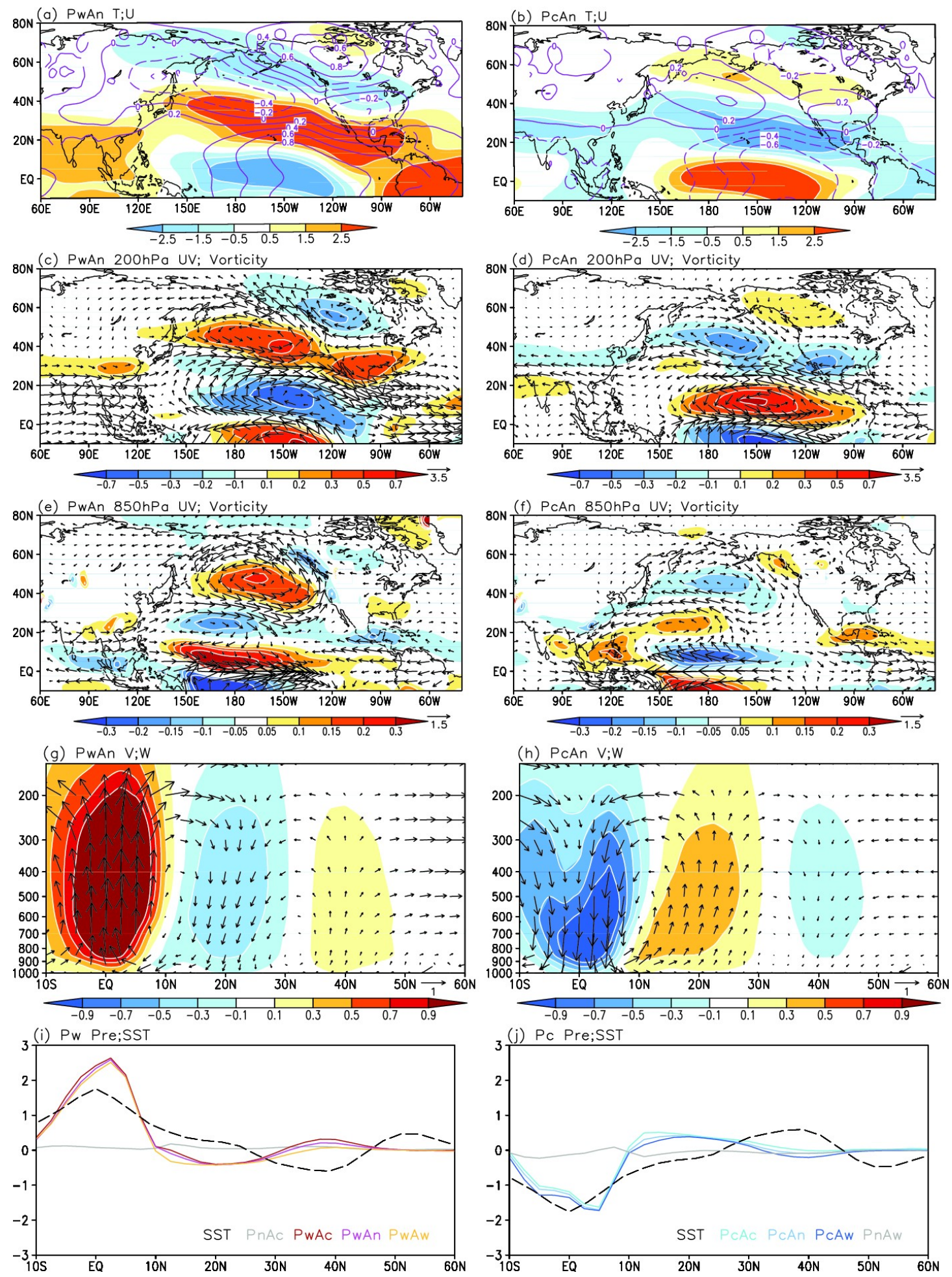

Fig. 7 Multi-model ensemble mean anomalies of annual mean (a) (b) air temperature (T,

158 from surface to $200 \mathrm{hPa}$, contours, $\mathrm{K}$ ) and $200 \mathrm{hPa}$ zonal wind (U, shaded, $\mathrm{m} \mathrm{s}^{-1}$ ); wind

159 (UV, $\mathrm{m} \mathrm{s}^{-1}$, vectors) and relative vorticity (scaled by 1e5, $\mathrm{s}^{-1}$, shaded) at (c) (d) $200 \mathrm{hPa}$,

160 and (e) (f) $850 \mathrm{hPa}$; (g) (h) meridional (V, $\mathrm{m} \mathrm{s}^{-1}$, vectors) and vertical (W, $10^{-3} \mathrm{~m} \mathrm{~s}^{-1}$,

161 shaded) circulation, and (i) (j) SST (scaled by $2,{ }^{\circ} \mathrm{C}$ ) and precipitation (Pre, mm day ${ }^{-1}$ )

162 over the Pacific (average $150^{\circ} \mathrm{E} \sim 120^{\circ} \mathrm{W}$ ), for PwAn (left column) and PcAn (right 
163 column). For convenience in comparing quantitatively the precipitation responses in

164 different experiments, the zonal-mean precipitation anomalies in experiments with the 165 warm (Pw) and cold IPO (Pc), as well as PnAc and PnAw, are illustrated in (i) and (j), respectively.
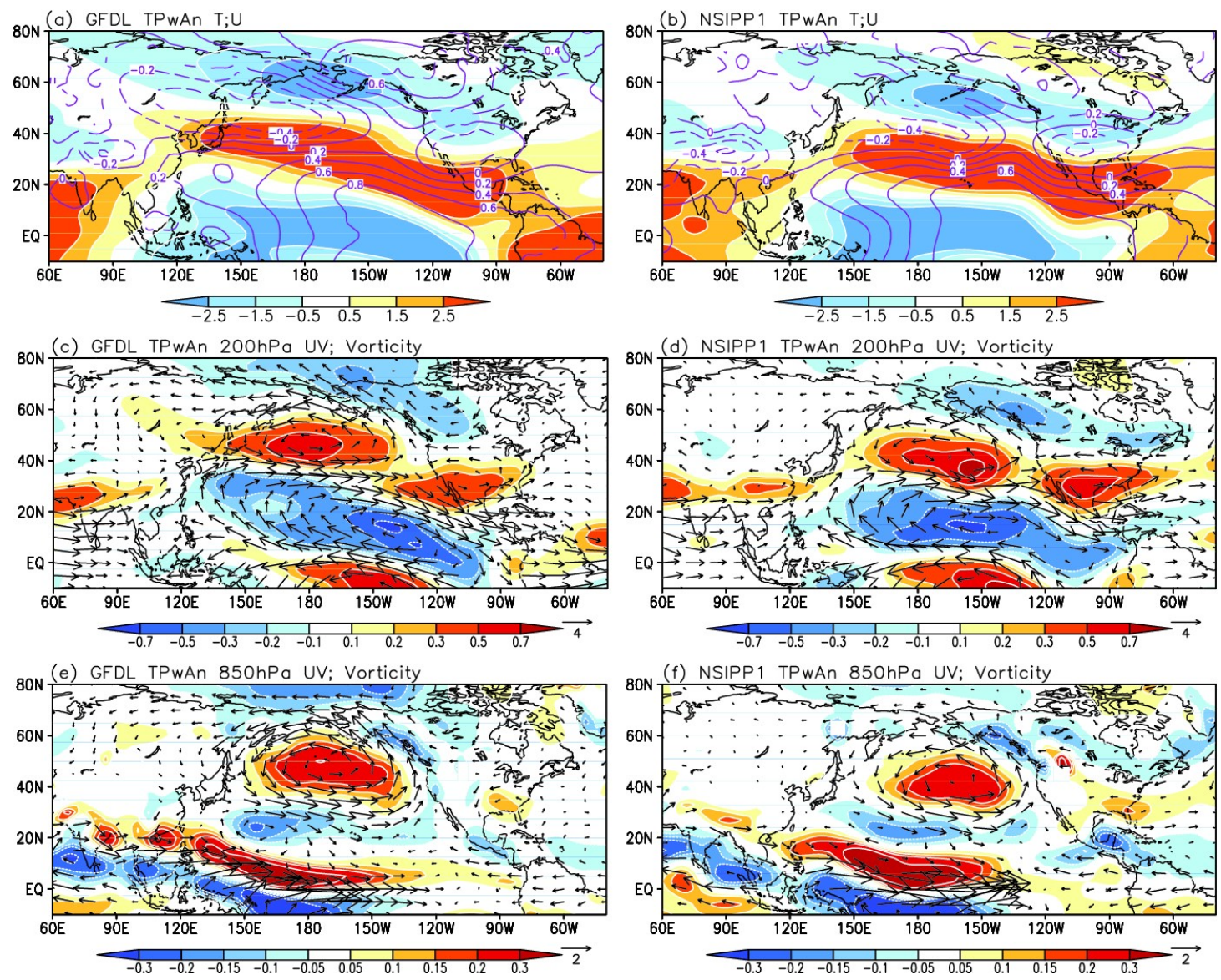

169 Fig. 8 Anomalies of annual mean (a) (b) air temperature (T, from surface to $200 \mathrm{hPa}$,

170 contours, $\mathrm{K}$ ) and $200 \mathrm{hPa}$ zonal wind (U, shaded, $\left.\mathrm{m} \mathrm{s}^{-1}\right)$; wind (UV, $\mathrm{m} \mathrm{s}^{-1}$, vectors) and

171 relative vorticity (scaled by $1 \mathrm{e} 5, \mathrm{~s}^{-1}$, shaded) at (c) (d) $200 \mathrm{hPa}$, and (e) (f) $850 \mathrm{hPa}$ for TPwAn in GFDL (left column) and NSIPP1 (right column). 

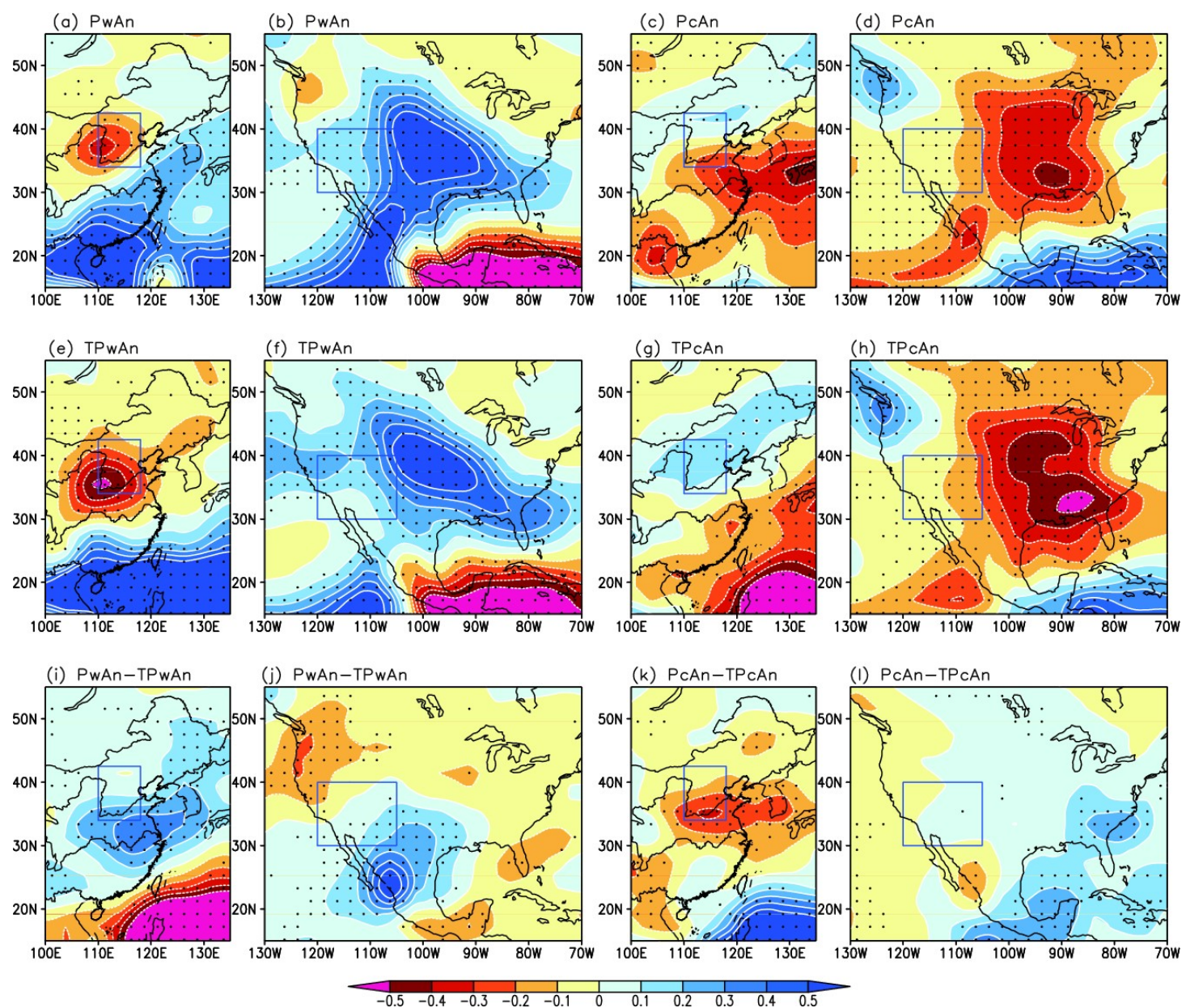

174 Fig. 9 Responses of annual mean precipitation ( $\mathrm{mm} \mathrm{day}^{-1}$, shaded) to the Pacific pattern

175 (PwAn and PcAn) and its tropical SST component (TPwAn and TPcAn) in GFDL. The dotted areas represent statistically significant anomalies at the $5 \%$ level.

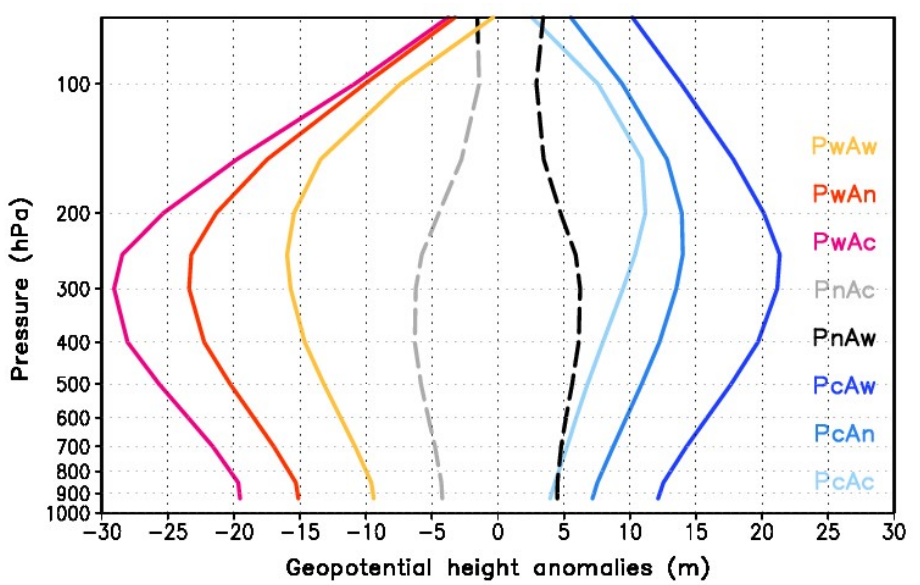

179 Fig. 10 Multi-model ensemble mean anomalies of annual mean geopotential height (m) over the northern North Pacific $\left(30^{\circ}-65^{\circ} \mathrm{N}, 160^{\circ} \mathrm{E}-140^{\circ} \mathrm{W}\right)$ from surface to $70 \mathrm{hPa}$. 

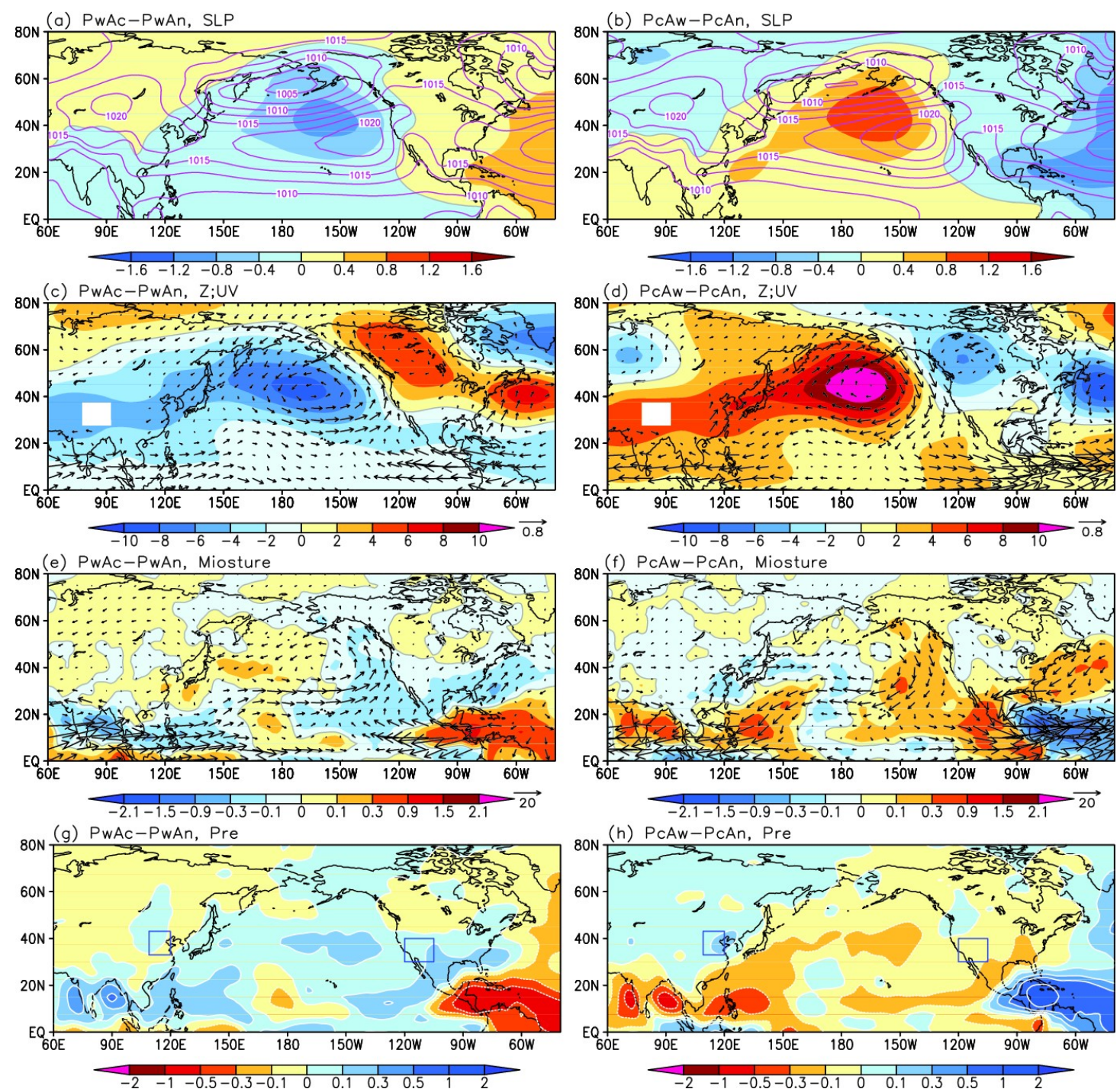

Fig. 11 Left column: Multi-model ensemble mean differences between PwAc and

183 PwAn: (a) SLP (hPa, shaded) and SLP climatology in PwAn (hPa, contours); (c)

$184500 \mathrm{hPa}$ geopotential height ( $\mathrm{Z}, \mathrm{m}$, shaded) and $850 \mathrm{hPa}$ wind ( $\mathrm{UV}, \mathrm{m} \mathrm{s}^{-1}$, vectors);

185 (e) column-integrated moisture divergence (mm day ${ }^{-1}$, shaded) and moisture flux

186 ( $\mathrm{g} \mathrm{cm}^{-1} \mathrm{~s}^{-1}$, vectors); (g) precipitation (Pre, $\mathrm{mm} \mathrm{day}^{-1}$, shaded). Right column is the same as left one, but for differences between PcAw and PcAn. 